\title{
Fixing the Energy Project Approval Process in Canada: AN EARLY ASSESSMENT OF BILL C-38 AND OTHER THOUgHTS
}

\author{
SANDY CARPENTER *
}

This article examines Bill C-38 and its potential impact on the current energy project assessment process in Canada, and considers whether Bill C-38 is likely to achieve its stated objectives. This article then considers how Bill C-38, as a proxy for the major energy review processes in Canada, addresses Aboriginal, stakeholder, and political issues and whether the Bill is likely to have any significant influence on these issues. On the assumption that Bill C-38 does not fully address these issues, this article then concludes with a further discussion of these influences and what might be done to address them.
Cet article porte sur le projet de loi C-38 et son impact éventuel sur les méthodes d'évaluation actuelles de projets énergétiques au Canada. L'article examine si le projet de loi en question atteindra les objectifs préconisés. L'auteur examine ensuite de quelle manière le projet de loi C-38, comme mandataire de méthodes d'examen énergétiques au Canada, aborde les questions politiques ainsi que celles des Autochtones et des intervenants et s'il influera vraiment sur ces questions. En supposant que le projet de loi C-38 n'aborde pas tout à fait ces questions, l'article se termine sur une discussion de ces influences et sur ce qui peut être fait pour les aborder.

\section{TABLE OF CONTENTS}

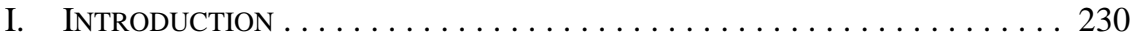

II. THE IMPACT OF BILL C-38 ON EXISTING

Federal Energy Project Assessment Processes . . . . . . . . . . . 232
A. AN OVERVIEW OF THE
CANADIAN ENVIRONMENTAL ASSESSMENT ACT 2012 . . . . . . . . . 232
B. THE APPLICATION OF THE CANADIAN ENVIRONMENTAL
ASSESSMENT ACt 2012 to CERTAin MAJOR EnERgy ProjeCts . . . . 240
C. DOES THE CANADIAN ENVIRONMENTAL ASSESSMENT ACT 2012
ACHIEVE ITS OBJECTIVES? . . . . . . . . . . . . . . . . . . . . 243

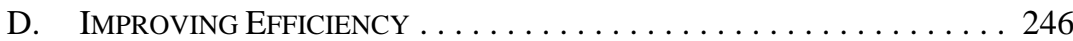
E. IMPROVING OUTCOMES . . . . . . . . . . . . . . . . . . . . . . 249

III. How DOES THE CANADIAN ENVIRONMENTAL ASSESSMENT ACT 2012

AdDRESS ABORIGINAL, STAKEHOLDER, AND POLITICAL IsSUES? . . . . . 251

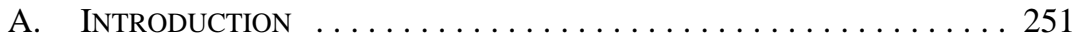

B. ABORIGINAL IsSUES . . . . . . . . . . . . . . . . . . . . . 251

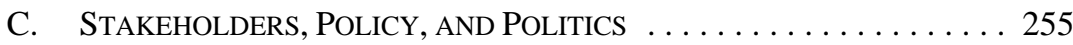

IV. A BROADER CONSIDERATION OF ABORIGINAL, STAKEHOLDER, AND POLITICAL IsSUES . . . . . . . . . . . . . . 262

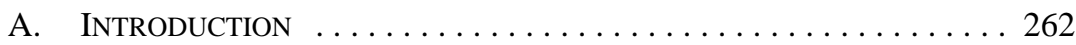

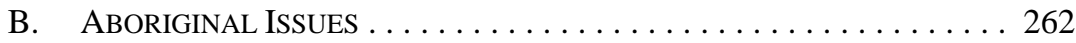

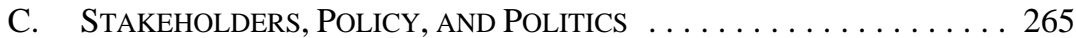

V. CONCLUSION .............................. 269

Partner, Fasken Martineau DuMoulin LLP, Calgary, Alberta. The views expressed within this article are solely those of the author, are based on the author's understanding at this point in time, and are subject to change at any time. Thank you to Dean Watt, also of Fasken Martineau, for his assistance with the article. 


\section{INTRODUCTION}

It was a dark and stormy night. Natural gas, a traditional supplier of jobs and revenue in the Northern Kingdom, was being displaced by a new source of supply in the Kingdom's southern neighbour and largest customer. Conversely, the price of oil — the black gold — had soared, but attempts to develop new trade routes into nearby markets were being disrupted. Perhaps worse, enemies of the Northern Kingdom, along with the Indigenous peoples of its western fringe, were attacking efforts to develop new markets for oil across the western ocean.

In response, King Stephen and his close advisors, Peter of Kent and Joe of Oliver, ${ }^{1}$ came up with a bold plan. They would replace the Kingdom's process which reviewed resource development projects, one that they considered unworkable, with a new one, ensuring that reviews were conducted within strict time limits, banishing foreign interference, and giving the King and his cohorts the final say over whether a proposed project would proceed. With these changes a new dawn would arrive and lightness would return to the Kingdom - or would it? The forces of darkness were already forming new coalitions and vowing war against the King and his advisors' efforts.

Let the battles begin.

Notwithstanding Canada's sporadic attempts to rid itself of the image of hewers of wood and drawers of water, its current fate seems disproportionally tied to its role as a commodity producer, including energy. In turn, that fate also appears to be tied to an emerging battle of epic proportions.

Many people perceive that Canada's ability to continue to rely on its resource wealth is increasingly removed from its ability to compete for a share of world markets, and is now more influenced by the review processes associated with their development. There is also a perception that resource development efforts are being double-teamed by influences beyond the scope of what has traditionally been addressed in these processes - such as Aboriginal, stakeholder, and political issues. Of course, others do not share these views. Their complaints are that while project review processes may give the impression of in-depth consideration, in practice, these are no more than a rubber stamp and often do not address what they consider to be the real issues associated with resource development.

All major energy projects in Canada are required to go through extensive review processes before they can proceed. However, as with other resource development projects, energy projects also appear to increasingly be at risk as a result of the processes that have been put in place to consider these projects and associated Aboriginal, stakeholder, and political issues. At a minimum, these factors can add cost and risk to a project. However, if the people who perceive that Canada needs to diversify its traditional energy markets are correct, failing 
to address these issues could also ultimately affect Canada's ability to attract investment, provide jobs, and to maintain its standard of living.

The writing of this article began as an attempt to address the current role of Aboriginal, stakeholder, and political issues on major energy review processes in Canada. Then, on 26 April 2012, apparently in response to some of the issues identified above, the Minister of Finance tabled Bill C-38. ${ }^{2}$ The Bill proposed to repeal the existing Canadian Environmental Assessment $\mathrm{Act}^{3}$ and to replace it with a new act, the Canadian Environmental Assessment Act 2012. ${ }^{4}$ CEAA 2012 proposed major changes to the federal environmental assessment process, which will be further discussed in this article.

This article examines Bill C-38 and its potential impact on the current energy project assessment process in Canada, and considers whether Bill C-38 is likely to achieve its stated objectives. This article then returns to the original topic to consider how Bill C-38, as a proxy for the major energy review processes in Canada, ${ }^{5}$ addresses Aboriginal, stakeholder, and political issues and whether the Bill is likely to have any significant influence on these issues. On the assumption that Bill C-38 does not fully address these issues, which seems to be supported by an initial review of the Bill, the article concludes with a further discussion of these influences and what might be done to address them.

Whether or not Bill C-38 ultimately achieves its purpose, the early indications are that it, in and of itself, may have crystallized the debate over the role of resource project review processes in Canada, and the lines are being drawn for what seems destined to be a protracted public, political, and legal battle. ${ }^{6}$ While this debate seems long overdue from the perspective of the potential influence of these processes on the development of Canada's energy resources, ironically, it comes at what may be a critical time for the energy industry in Canada, and the likely outcome of this confluence - that the battle over Bill C-38 will be fought, at least in part, as part of the review processes for some of the current major energy projects in Canada - will add further risks and delay to these projects. In hindsight, this may turn out to be an unwelcome development, but there does not appear to be any chance of turning back at this point. Given this, like our mythical Northern Kingdom, let the battles begin.

Bill C-38, An Act to implement certain provisions of the budget tabled in Parliament on March 29, 2012 and other measures, 1st Sess, 41st Parl, 2012 (assented to 29 June 2012), SC 2012 c 19 [Bill C-38]. Bill C-38 is also known as the Jobs, Growth and Long-term Prosperity Act. At the time of the writing of this article, Bill C-38 was under review in Parliament. Bill C-38 was subsequently proclaimed into force prior to publication.

3 SC 1992, с 37 [CEAA].

$4 \quad$ The full text of the Canadian Environmental Assessment Act 2012 [CEAA 2012] is found in section 52 of Bill C-38, supra note 2. Section 66 of Bill C-38 repeals CEAA.

$5 \quad$ While the federal environmental review process is not the only review process that most major energy projects in Canada must satisfy, it does tend to be a common denominator in these processes (in other words, most major energy projects are required to undergo a federal environmental assessment along with satisfying other requirements). Given this, Bill C-38 and its impacts on the federal environmental assessment process appear to be a reasonable starting point for this discussion.

$6 \quad$ See e.g. Gloria Galloway, "Hundreds of websites go dark to decry Tory budget bill," The Globe and Mail (4 June 2012), online: The Globe and Mail <http://www.theglobeandmail.com/news/politics/ ottawa-notebook/hundreds-of-websites-go-dark-to-decry-tory-budget-bill/article4229609/>. 


\section{THE IMPACT OF BILL C-38 ON EXISTING Federal Energy Project Assessment Processes}

CEAA was first introduced in Parliament in 1992 and was brought into force in 1995. Since that time, it has been used to complete tens of thousands of environmental assessments and has been the subject of a number of legislated reviews ${ }^{7}$ and significant jurisprudence. ${ }^{8}$

On 26 April 2012, the Minister of Finance introduced Bill C-38, intended in part to repeal $C E A A$ and to replace it with a new federal environmental assessment process. The introduction appeared to reflect the federal government's conclusion that, notwithstanding the accumulated experience and jurisprudence under $C E A A$, no amount of amendment could address its perceived flaws. ${ }^{9}$

This part of the article examines the changes to the major energy project assessment process under CEAA 2012 and whether CEAA 2012 has the potential to live up to what appear to be the federal government's expectations. The article does so by briefly explaining some of the key provisions of CEAA 2012 and then comparing the Act against what appear to be its objectives. ${ }^{10}$

\section{A. AN OVERVIEW OF THE CANAdian ENVIRonmental ASSESSMENT ACt 2012}

To understand CEAA 2012, a brief review of the previous CEAA may be helpful. Under $C E A A$, projects or activities were not separately identified as requiring a review. Rather, a project or activity "triggered" CEAA if it touched on certain aspects of federal jurisdiction — and was not excluded under other provisions. ${ }^{11}$ In particular, an assessment under CEAA was required if a federal authority was the proponent of a project, granted money or another form of financial assistance to a project, granted an interest in land to enable a project to be carried out, or issued certain permits or licences in connection with a project. ${ }^{12}$ The latter provision was the trigger for many of the CEAA reviews of major energy projects.

Once triggered, the type and size of the project or activity determined the level of review required: either a screening or a comprehensive study. ${ }^{13}$ Notwithstanding the perception that

The most recent review took place earlier this year. See House of Commons, Standing Committee on Environment and Sustainable Development, Statutory Review of the Canadian Environmental Assessment Act: Protecting the Environment, Managing our Resources (March 2012) (Chair: Mark Warawa), online: Government of Canada Publication <http://publications.gc.ca/collections/collection_ 2012/parl/XC50-1-411-01-eng.pdf> [Statutory Review]. See e.g. MiningWatch Canada v Canada (Fisheries and Oceans), 2010 SCC 2, [2010] 1 SCR 6 (considering sections 15 and 21 of CEAA); Friends of the West County Assn v Canada (Minister of Fisheries and Oceans), [2000] 2 FC 263 (considering sections 5 and 15 of CEAA). Note that the Statutory Review, supra note 7, while recommending major changes to CEAA, did not recommend repealing it. However, the Standing Committee on Environment and Sustainable Development may not have considered this within their mandate. It should be noted that this article is not intended to provide a comprehensive review of CEAA 2012 but only to address it in the context of major energy projects. There are significant aspects of CEAA 2012 that are designed to address issues with the application of $C E A A$ in other contexts which are beyond the scope of this article.

CEAA, supra note 3, ss 5(1), 7, 7.1.

Ibid, s 5(1).

See Comprehensive Study List Regulations, SOR/94-638. 
there is a significant difference between these approaches, screening reports and comprehensive studies are often closer in effort for energy projects than perhaps suggested by their names. Both screenings and comprehensive studies require consideration of the environmental effects of a project and the significance of these effects. ${ }^{14}$ Comprehensive studies, in turn, require the consideration of certain additional factors. ${ }^{15}$ In addition to a screening or comprehensive study, projects or activities can also be referred to a review panel or mediation under $C E A A^{16}$

A screening, comprehensive study, or review panel is effectively required to come to a conclusion regarding whether a proposed project or activity is likely to cause significant adverse environmental effects. If a proposed project or activity is not likely to cause significant adverse environmental effects, the "responsible authority" can grant the necessary authorizations for the project or activity. If significant adverse environmental effects are anticipated, the responsible authority can only grant authorization if the effects of the project or activity can be justified in the circumstances. ${ }^{17}$

Various levels of public participation are provided for under CEAA. For screenings, public participation is at the discretion of the responsible authority.$^{18}$ For comprehensive studies, the responsible authority is required to ensure that there are various opportunities for public involvement. ${ }^{19}$ For review panels, full public hearings are required. ${ }^{20}$ There are no legislated time limits required under $C E A A$, however, various measures have been put in place over time to attempt to ensure that $C E A A$ reviews take place on a timely basis. ${ }^{21}$

In contrast, CEAA 2012 establishes a defined set of “designated projects” that will require assessment. A designated project "means one or more physical activities that $(a)$ are carried out in Canada or on federal lands; $(b)$ are designated by regulations made under paragraph 84(a) or designated in an order made by the Minister [of the Environment] under subsection 14(2); and (c) are linked to the same federal authority as specified in those regulations or that order." 22 The discretion of the Minister of the Environment (the Minister) to designate a project is based on her or his opinion that "either the carrying out of the physical activity may cause adverse environmental effects or public concerns related to those effects may warrant the designation." 23

Once it has been determined that a proposed activity is a designated project, a second step may be required for some projects to determine if an assessment is actually required. Unless a designated project falls under the jurisdiction of the National Energy Board (NEB) or the Canadian Nuclear Safety Commission (CNSC), the proponent of a designated project is

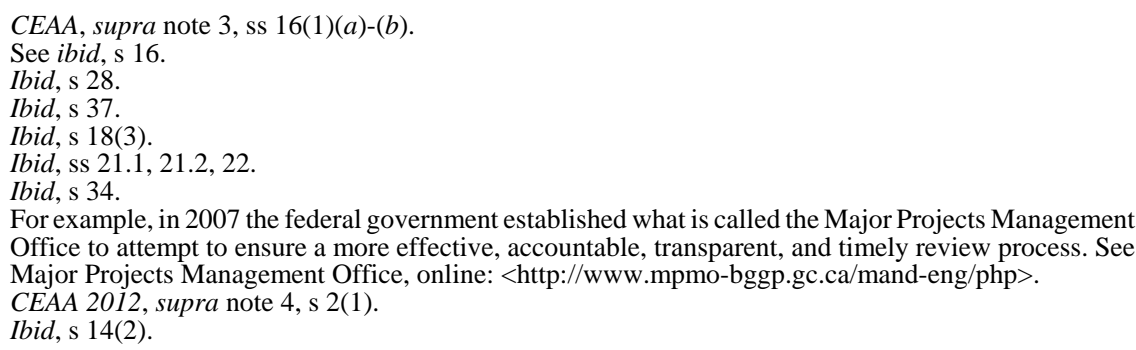
Office to attempt to ensure a more effective, accountable, transparent, and timely review process. See Major Projects Management Office, online: <http://www.mpmo-bggp.gc.ca/mand-eng/php>. CEAA 2012, supra note 4, s 2(1).

Ibid, s 14(2). 
required to provide the Canadian Environmental Assessment Agency (the Agency) with a project description containing certain information. ${ }^{24}$ Once the Agency determines that the project description is complete and contains sufficient detail, the Agency must conduct a "screening" of the project to determine if an environmental assessment is required. ${ }^{25}$ This screening is based on the project description, the possibility that carrying out the designated project may cause adverse environmental effects, any comments received from the public on the screening, and the results of any previously conducted regional studies ${ }^{26}$ Consistent with the approach of establishing timelines for various steps under CEAA 2012, this screening must be completed within 45 days from the date of the posting of the completed project description. $^{27}$

If the Agency decides that an assessment is required — or the assessment is necessary in the case of NEB or CNSC-regulated projects - an environmental assessment under CEAA 2012 would then take place. This assessment begins with the relevant authority posting a notice advising of the commencement of the assessment on an Internet site maintained by the Agency. ${ }^{28}$

The environmental assessment must take the following factors into account:

(a) the environmental effects of the designated project, including the environmental effects of malfunctions or accidents that may occur in connection with the designated project and any cumulative environmental effects that are likely to result from the designated project in combination with other physical activities that have been or will be carried out;

(b) the significance of the effects referred to in paragraph (a);

(c) comments from the public — or, with respect to a designated project that requires that a certificate be issued in accordance with an order made under section 54 of the National Energy Board Act, any interested party — that are received in accordance with this Act;

(d) mitigation measures that are technically and economically feasible and that would mitigate any significant adverse environmental effects of the designated project;

(e) the requirements of the follow-up program in respect of the designated project;

(f) the purpose of the designated project;

(g) alternative means of carrying out the designated project that are technically and economically feasible and the environmental effects of any such alternative means;

(h) any change to the designated project that may be caused by the environment;

Ibid, s 8(1). This description must include the information prescribed by regulations made under section 84(b).

Ibid, s 10 (a).

Ibid. Note that CEAA 2012 encourages the use of regional studies to examine potential cumulative effects in sections 73 and 74.

Ibid, s 10(b).

Ibid, s 17. An "Internet site" is defined in section 2(1) of the Act. 
(i) the results of any relevant study conducted by a committee established under section 73 or 74 ; and

(j) any other matter relevant to the environmental assessment that the responsible authority, or — if the environmental assessment is referred to a review panel — the Minister, requires to be taken into account. $^{29}$

Readers familiar with CEAA will note that these considerations under CEAA2012 are very similar to the factors that needed to be considered in a comprehensive study under CEAA. ${ }^{30}$ The exceptions seem to be the deletion of the wording regarding "the need for the project and alternatives to the project" 31 and the deletion of "the capacity of renewable resources that are likely to be significantly affected by the project to meet the needs of the present and those of the future."32

However, unlike $C E A A$, where once an environmental assessment was required this effectively took into account all potential effects regardless of whether these were primarily related to matters of provincial or federal jurisdiction, CEAA 2012 attempts to focus the assessment on effects associated with certain matters of federal jurisdiction. These are:

(a) a change that may be caused to the following components of the environment that are within the legislative authority of Parliament:

(i) fish as defined in section 2 of the Fisheries Act and fish habitat as defined in subsection 34(1) of that Act,

(ii) aquatic species as defined in subsection 2(1) of the Species at Risk Act,

(iii) migratory birds as defined in subsection 2(1) of the Migratory Birds Convention Act, 1994, and

(iv) any other component of the environment that is set out in Schedule 2;

(b) a change that may be caused to the environment that would occur

(i) on federal lands,

(ii) in a province other than the one in which the act or thing is done or where the physical activity, the designated project or the project is being carried out, or

(iii) outside Canada; and

(c) with respect to aboriginal peoples, an effect occurring in Canada of any change that may be caused to the environment on

Ibid, s 19(1).

These factors are outlined in CEAA, supra note 3, ss 16(1)-(2).

Ibid, s 16(1)(e). Although these factors are discretionary under CEAA2012, they have been included for a number of major energy projects.

Ibid, s 16(2)(d). 
(i) health and socio-economic conditions,

(ii) physical and cultural heritage,

(iii) the current use of lands and resources for traditional purposes, or

(iv) any structure, site or thing that is of historical, archaeological, paleontological or architectural significance. $^{33}$

CEAA 2012 further specifies that "a change, other than those referred to in paragraphs (1)(a) and (b), that may be caused to the environment and that is directly linked or necessarily incidental to a federal authority's exercise of a power or performance of a duty or function that would permit the carrying out, in whole or in part, of the physical activity, the designated project or the project”34 is also to be taken into account. Unless a designated project has been referred to a review panel, the relevant authority must conduct an environmental assessment of the project addressing the identified factors and then prepare a report with respect to that assessment. $^{35}$

In certain cases, as previously indicated, the relevant authority must ensure that the public is provided with an opportunity to participate in the environmental assessment. ${ }^{36}$ The minimum level of public participation appears to be the opportunity to comment on the draft assessment report before it is finalized. ${ }^{37}$ There may be more required to ensure a minimum level of public participation, but this is not clear. ${ }^{38}$ To facilitate public participation on certain types of projects, the Agency must establish a participant funding program for those designated projects that include certain designated physical activities or that fall within a designated class of activities. ${ }^{39}$ Presumably, these will be what, by some measure, are considered the more significant designated projects.

During the environmental assessment, the relevant authority must also offer to consult and co-operate with any other jurisdictions that are also responsible for carrying out an assessment of that particular project. ${ }^{40}$ However, CEAA 2012 goes further than this. Unless the assessment is being conducted by the NEB or the CNSC - or has already been referred to a review panel - a province may request that its environmental assessment process be

CEAA 2012, supra note 4, s 5(1).

Ibid, s 5(2)(a). Considerations include any impact of these changes on "(i) health and socio-economic conditions, (ii) physical and cultural heritage, or (iii) any structure, site or thing that is of historical, archaeological, paleotological or architectural significance” (ibid, s 5(2)(b)).

Ibid, s 22.

Ibid, s 24. Note that if the carrying out of the designated project requires that a certificate be issued under section 54 of the National Energy Board Act, RSC 1985, c N-7 [NEB Act], the NEB is only required to ensure that any "interested party" has the opportunity to participate. This is discussed further below.

CEAA 2012, ibid, s 25.

As indicated, section 24 of CEAA 2012, ibid, provides that the responsible authority must ensure that the public has the opportunity to participate in the environmental assessment. Section 25 then goes on to indicate that the public must have the opportunity to comment on the draft assessment report before it is finalized. These appear to refer to separate opportunities, but it's not completely clear if this is what was intended. Ibid, s 58.

Ibid, s 18. Note that section 18 also provides that the Minister is also responsible for doing so in the event that the assessment has been referred to a review panel. 
substituted for the federal environmental assessment process under CEAA2012. The Minister must agree to this substitution as long as they believe that the province's environmental assessment process is an "appropriate substitute." ${ }^{41}$ An appropriate substitute appears to be one that includes a consideration of the same factors that would be addressed if a federal assessment took place, that provides for participation by the public, and that meets any other conditions established by the Minister. ${ }^{42}$ If these requirements are met, the environmental assessment would be conducted by the province, but the final decision-making would still be reserved to the relevant federal authority. ${ }^{43}$

In some circumstances, the Governor in Council (GIC) is authorized to go even further and exempt the designated project from the application of CEAA 2012 (in other words, the GIC may exempt the designated project from any federal decision). The GIC may do this if the substituted process considers the same overarching matters that need to be addressed under CEAA 2012 (for example, the significance of the project's effects, the necessary mitigation measures, the implementation of a follow-up program, or any further conditions that the Minister requires to be met). ${ }^{44}$

For designated projects that require a certificate under section 54 of the NEB Act, the NEB must also ensure that the environmental assessment is conducted and that a report is prepared. However, in these circumstances, the NEB is only required to ensure that "interested parties" have the opportunity to participate, rather than any members of the public. ${ }^{45}$ This replicates the current requirement under the NEB Act. ${ }^{46}$ Whether a person is an interested party requires a determination by the NEB that the person is directly affected by the carrying out of the designated project or, in the NEB's opinion, that the person has relevant information or expertise to contribute to the process. ${ }^{47}$

In its report, the NEB must ensure that it sets out its recommendations to the GIC, the ultimate decision-maker on certificates under section 54 , as to whether the designated project is likely to cause significant effects and, if so, whether those effects can be justified. ${ }^{48}$ The NEB is also required to set out its recommendations on the follow-up program that should be implemented for the project. ${ }^{49}$ The NEB is required to submit its report on the environmental assessment at the same time as it submits its recommendations under section 52 of the NEB Act on the certificate itself. ${ }^{50}$ Following the submission of the NEB's report,

Ibid, s 32(1). Note that the Minister also has the discretion to substitute the environmental assessment process established under a land claims agreement or Aboriginal self-government legislation.

Ibid, s 34(1). Note that other considerations are that the public will have access to records in relation to the assessment to enable their meaningful participation, that a report will be prepared at the end of the assessment, and that the report will be made available to the public. These were not included above since these are standard features of many environmental assessment regimes.

This final decision-making may also be done by an organization established under a land claims agreement or self-government legislation.

CEAA 2012, supra note 4, s 37.

Ibid, s 28.

See section 53 of the NEB Act, supra note 36, dealing with objections from interested persons.

See the definition of an "interested party" in CEAA 2012, supra note 4, ss 2(1)-(2).

Ibid, s 29(1)(a).

Ibid, s 29(1)(b).

Ibid, s 29(2). 
the GIC can refer any of the NEB's recommendations back to the NEB for reconsideration. ${ }^{51}$ The GIC's order may direct the NEB to “conduct the reconsideration taking into account any factor specified in the order and it may specify a time limit within which the [NEB] must complete its reconsideration." 52

Instead of going through the normal assessment process, the Minister has the power to establish a review panel to carry out an environmental assessment, except for matters over which either the NEB or the CNSC has jurisdiction. ${ }^{53}$ In doing so, the Minister has to consider whether the designated project might cause significant environmental effects, public concerns related to those effects, ${ }^{54}$ and opportunities to cooperate with other jurisdictions who also have the responsibility of conducting an environmental assessment of the project. ${ }^{55}$ The referral to a review panel must be made within 60 days of the notice of commencement of the assessment. ${ }^{56}$

If the Minister does refer a project to a review panel, the Minister must establish time limits for each of the establishment of the review panel, when the panel has to submit its report, and when the Minister must issue her or his decision statement on the project. ${ }^{57}$ These time limits cannot exceed a total of 24 months, unless they are subsequently extended to allow for co-operation with another jurisdiction or to take into account special circumstances involving the project. ${ }^{58}$ The Minister can also establish a joint review panel with another jurisdiction, as she or he could under $C E A A$, again with the exception of projects under the jurisdiction of the NEB or the CNSC. ${ }^{59}$

If a matter is referred to a review panel, the review panel must ensure that the information that it uses to conduct the environmental assessment is available to the public and must hold hearings in a manner that offers "interested parties" an opportunity to participate. ${ }^{60}$ The definition of interested parties is the same as for projects that require a certificate under section 54 of the NEB Act. ${ }^{61}$ Notwithstanding this limitation, it appears that there is some role envisaged for members of the public who do not qualify as interested parties, although it is not clear what this role is. The review panel's report must include a summary of any comments received "from the public," not just interested parties, suggesting a broader class of participants than just interested parties. ${ }^{62}$ In addition, for review panel processes, CEAA 2012 expressly requires the Agency to establish a participant funding program to facilitate the participation of the public in the environmental assessment, although, again, it does not provide any details on what this participation is expected to be. ${ }^{63}$

Ibid, s 30. Note that it appears that there is the possibility of two rounds of reconsideration (see section 30(6)). However, this is not completely clear, since section 30(5) provides that the NEB's reconsideration report is final and binding.

Ibid, s 30(2).

Ibid, s 38(6).

Note that this is a departure from $C E A A$, under which general public concerns were sufficient to allow the Minister to refer a project to a review panel.

CEAA 2012, supra note 4, s 38(2).

Ibid, s 38(1).

Ibid, s 38(3).

Ibid, s 38(4).

Ibid, s 38(6).

Ibid, ss 43(1)(b)-(c).

Again, refer to the definition of an "interested party" in sections 2(1) and 2(2) of CEAA 2012.

Ibid, s 43(1)(d).

Ibid, s 57. 
Following its hearings, a review panel must prepare a report that sets out the review panel's rationale, conclusions, and recommendations with respect to the project, including any required mitigation measures and follow-up program, and a summary of any comments received from the public. ${ }^{64}$ Significantly, if the review panel fails to submit its report within the time limit set by the Minister, including any extensions, the Minister must terminate the review panel's assessment. ${ }^{65}$ The Minister also has the power to terminate a review panel assessment on a pre-emptory basis if she or he is of the opinion that the review panel will not be able to complete their assessment within the established period of time ${ }^{66}$ If a review panel assessment is terminated, the Agency is required to complete the assessment in accordance with the directives established by the Minister. ${ }^{67}$

Once the Minister receives the review panel's report, the Minister must make the report available to the public. ${ }^{68}$ The panel is also required to clarify any of its conclusions and recommendations if the Minister requests that it do so. ${ }^{69}$

Once the report on the environmental assessment has been completed, ${ }^{70}$ either the relevant authority or the Minister, in the case of the Agency and review panel assessments, must make a decision on the project. ${ }^{71}$ This decision normally must be made within 365 days of the date that the notice of the commencement of the assessment is posted on the Agency's Internet site, but is extended to two years for review panel processes. ${ }^{72}$ The Minister can further extend this period by up to three months if she or he thinks that additional time is necessary to either co-operate with another jurisdiction or to take into account "circumstances that are specific to the project." ${ }^{\text {73 }}$ The GIC is the only entity that can order a further extension. ${ }^{74}$ Notwithstanding the completion of a review panel process, if the Minister believes that she or he needs further information, including studies, to make a decision on the proposed project, the Minister can require the proponent to provide this information before the Minister makes their decision. ${ }^{75}$

If the decision-maker concludes that the designated project is unlikely to cause significant adverse effects, the decision-maker needs to establish the conditions with which the proponent must comply. ${ }^{76}$ These conditions are required to consist of the implementation of

$64 \quad$ Ibid, s 43(1)(d).

Ibid, s 49(1). Note that before terminating an assessment by a jointly established review panel, the Minister must consult with the jurisdiction with which the arrangement was entered into, but still appears to be obligated to terminate the assessment (see ibid, s 49(3)).

$66 I$ Ibid, s 49(2). Again, before terminating an assessment by a jointly established review panel, the Minister must consult with the jurisdiction with which the arrangement was entered into (see ibid, s 49(3)).

Ibid, s 50 .

Ibid, s 46.

Ibid, s 43(1)(f).

This includes a report under a substituted process: ibid, ss 35-36.

Ibid, s 27(1). Note that this provision does not apply when the designated project requires a certificate under section 54 of the NEB Act, supra note 36, as per section 27(7) of CEAA 2012.

$C E A A 2012$, ibid, s 27(2). Note that this period does not include any time that is required for the proponent to collect any further information or conduct any further studies that may be required (see ibid, s 27(6)).

Ibid, s 27(3).

Ibid, s 27(4).

Ibid, s 47.

Ibid, ss 52(1), 53(1). 
the mitigation measures that were taken into account in assessing the significance of the adverse environmental effects and the implementation of a follow-up program. ${ }^{77}$

Alternatively, if the decision-maker concludes that the designated project is likely to cause significant effects, the designated project would be referred to the GIC to decide whether these effects can be justified in the circumstances. ${ }^{78}$ If the GIC decides that the effects can be justified, the decision-maker must, again, establish conditions with which the proponent of the designated project must comply. ${ }^{79}$

Once a decision has been made, the decision-maker must issue what has been called a "decision statement" on the project. The decision statement informs the proponent of the decision and the conditions that have been established for the project. ${ }^{80}$ For licences under the Nuclear Safety and Control Act, ${ }^{81}$ the decision statement is considered to be part of the licence. $^{82}$ Similarly, for authorizations under the NEB Act or the Canada Oil and Gas Operations $A c t,{ }^{83}$ the decision statement is considered to form a part of those authorizations. ${ }^{84}$

The decision statement and attached conditions are significant. Under section 6 of CEAA 2012, a proponent must not do anything in carrying out the project, or in connection with carrying out the project, unless the proponent complies with the conditions in the decision statement. Failure to comply with these conditions can result in an order against the proponent requiring it to comply with the $A c t,{ }^{85}$ injunction proceedings, ${ }^{86}$ or an offence. ${ }^{87}$

\section{B. The Application of the CANAdian ENVIRONMENTAL ASSESSMENT ACt 2012 to Certain Major Energy Projects}

This section briefly describes the process that would be followed under CEAA 2012 for certain types of energy projects. This review does not describe the process that would take place for all types of energy projects in all jurisdictions, but attempts to provide an overview of the process for certain types of projects to assist in understanding the new Act and the subsequent discussion.

Based on the categorization of projects in CEAA 2012, it would appear that most major energy projects are likely to fall within three broad categories:

(a) primarily intra-provincial projects;

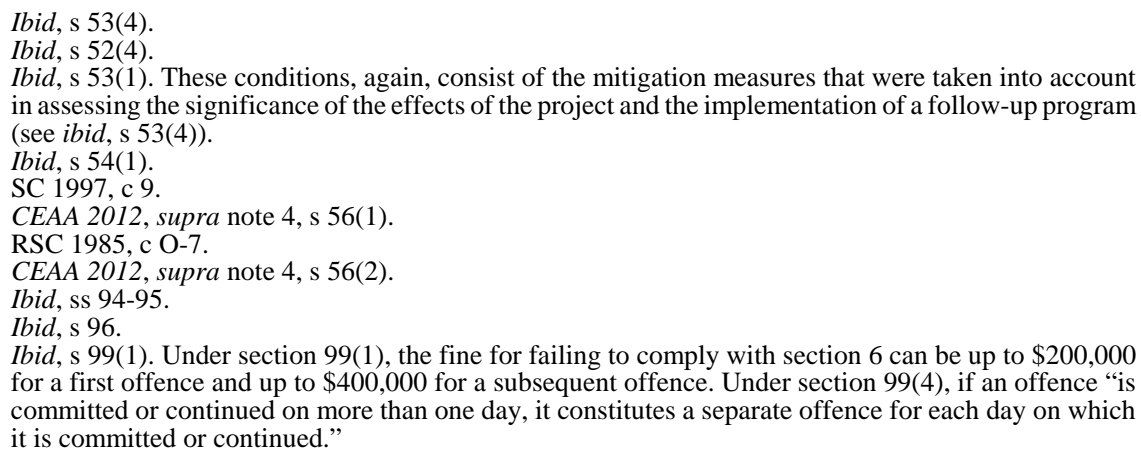

Ibid, s 53(1). These conditions, again, consist of the mitigation measures that were taken into account in assessing the significance of the effects of the project and the implementation of a follow-up program (see ibid, s 53(4)).

Ibid, s 54(1).

SC 1997, с 9 .

CEAA 2012, supra note 4, s 56(1).

RSC 1985, с O-7.

CEAA 2012, supra note 4, s 56(2).

Ibid, ss $94-95$.

Ibid, s 96.

Ibid, s 99(1). Under section 99(1), the fine for failing to comply with section 6 can be up to $\$ 200,000$ for a first offence and up to $\$ 400,000$ for a subsequent offence. Under section 99(4), if an offence "is committed or continued on more than one day, it constitutes a separate offence for each day on which it is committed or continued." 
(b) NEB-regulated projects that do not require certificates under section 54 of the NEB Act; and

(c) NEB-regulated designated projects that do require certificates under section 54 of the NEB Act. ${ }^{88}$

Primarily intra-provincial major energy projects would be projects such as oil sands projects, hydroelectric facilities, and large intra-provincial pipelines and transmission lines. Given the magnitude of these projects, they are likely to be included on the list of designated projects under CEAA 2012. They are also likely to trigger provincial environmental assessment processes and other provincial approval processes.

As previously discussed, the first step associated with the federal portion of the assessment of large intra-provincial designated projects would occur when the proponent files a project description for the project with the Agency. The Agency would then conduct a screening to determine if a federal environmental assessment is required. ${ }^{89}$ As mentioned, this screening is based on the project description, the possibility that carrying out the project may cause adverse environmental effects, any comments received by the public, the results of any previously conducted regional cumulative effects studies, ${ }^{90}$ and must be completed within 45 days from the date of the posting of the project description. ${ }^{91}$

It is expected that most major energy projects would require an assessment under CEAA 2012. However, this does not mean that all projects would have to go through an assessment. Given the focus on specific federal matters in section 5 of the Act, there is some chance that the Agency could find that no federal environmental assessment is required.

Assuming that a federal environmental assessment is required, there is an array of means under which this could take place. The Agency could undertake its own assessment while consulting and co-operating with the relevant provincial environmental assessment authority. ${ }^{92}$ However, if the province in question requests that its environmental assessment process be substituted for the federal process, and this process is considered to be an appropriate substitute, ${ }^{93}$ the Minister is obligated to allow the provincial environmental assessment to stand in the place of the federal process. ${ }^{94}$ Under this substituted process, the

For the purpose of this level of the analysis, I have chosen to arbitrarily define major energy projects as excluding those projects under the Nuclear Safety and Control Act. We have also not considered projects regulated by the Canada-Newfoundland Offshore Petroleum Board or the Canada-Nova Scotia Offshore Petroleum Board at this point in time.

CEAA 2012, supra note 4, s 10.

Ibid, s 10(a).

Ibid, s 10 .

Ibid, s 18. Note that section 18 also provides that the Minister is responsible for consulting and cooperating with the relevant provincial environmental assessment authority in the event that the assessment has been referred to a review panel.

Ibid, s 34(1). Note that other considerations include that the public will have access to records in relation to the assessment to enable their meaningful participation, that a report will be prepared at the end of the assessment, and that the report will be made available to the public. These were not discussed above, since these are standard features of many environmental assessment regimes. An appropriate substitute appears to be one that includes a consideration of the factors that would be considered in a federal assessment, that provides for participation by the public, and that meets any other conditions established by the Minister. See ibid, s 34(1) for further details.

$94 \quad$ Ibid, s 32(1). Note that the Minister also has the discretion to substitute the environmental assessment process established under a land claims agreement or Aboriginal self-government legislation. 
environmental assessment would be conducted by the province, ${ }^{95}$ but the Minister would still have to make the final decision on the project from a federal perspective. The GIC can also go further and exempt the project from the application of the Act. ${ }^{96}$ In such a case, no federal assessment, and no federal decision, would be required.

A further alternative to an assessment taking place by the Agency or under a provincial process is for the Minister to refer the assessment to a review panel, or to a joint review panel. As indicated, the Minister is required to make this decision within 60 days of the notice of commencement of the environmental assessment. ${ }^{97}$ Given this, it appears that a province may be able to avoid the risk of a project being referred to a review panel by requesting that its own provincial environmental assessment process be substituted for the federal process before the Minister makes this decision.

If the Agency does end up undertaking an assessment of an intra-provincial project, it must provide the opportunity for members of the public to comment on the draft assessment report before it is finalized. ${ }^{98}$ As indicated, it is not clear if there needs to be further opportunities for public participation, but it does appear that there is at least the discretion to do so. ${ }^{99}$ The Agency assessment would consider the factors set out in section 19 , focusing on the federal matters set out in section 5 .

The Agency's assessment report must be finalized and a decision made by the Minister within 365 days of the notice of commencement of the environmental assessment, subject to any requests for information from the proponent, or any extensions. In this circumstance, or if a substituted provincial assessment is forwarded to the Minister for a decision, the project would be allowed to proceed so long as it is unlikely to cause significant effects or, if it is, if the GIC decides that these effects are justified. The decision-maker would then issue a decision statement for the project including any conditions. The proponent would be required to comply with these conditions.

If a review panel or joint review panel process is established, the assessment and report would be completed by the review panel. In doing so, the review panel must ensure that the information that it uses in conducting its assessment is available to the public and it must hold hearings in a manner that offers interested parties an opportunity to participate. ${ }^{100}$ As indicated, it appears that there is some role for members of the public who do not qualify for interested party status, but it is not clear what this is. ${ }^{101}$

The environmental assessment may also be conducted by an organization established under a land claims agreement or self-government legislation.

CEAA 2012, supra note 4, s 37.

Ibid, s 38(1).

Ibid, s 25.

As previously discussed, section 24 of CEAA 2012, ibid, provides that the responsible authority must ensure that the public has the opportunity to participate in the environmental assessment. Section 25 then goes on to indicate that the public must have the opportunity to comment on the draft assessment report before it is finalized. These would appear to refer to separate opportunities, but it is not clear if this is what was intended.

$100 \quad$ Ibid, ss 43(1)(b)-(c).

$101 \mathrm{Ibid}, \mathrm{s} 43(1)$ (d). See also section 57, requiring the establishment of participant funding to allow members of the public to participate in review panel processes. 
In this event, the review panel's report, and the Minister's subsequent decision, must take place within two years from the notice of commencement of the environmental assessment (again assuming no further information is requested from the proponent and there are no further extensions). As above, the proponent would be required to comply with any conditions made with respect to the project.

The process for an NEB-regulated project that does not involve a certificate under section 54 of the NEB Act appears more straightforward - primarily as a result of there being only one process, and this process being carried out in all instances by the NEB. In this event, there is no screening process required..$^{102}$ As a result, the project would proceed immediately to an assessment carried out by the NEB.

The NEB is required to consult and co-operate with any other jurisdiction that may be responsible for conducting an environmental assessment of the designated project, but a province cannot request a substitution for these types of projects. ${ }^{103}$ There is also no ability for the GIC to exempt these projects or for the Minister to refer the assessment to a review panel. ${ }^{104}$

As with an Agency-led assessment, the NEB's assessment must at least provide the opportunity for members of the public to comment on the draft assessment report before it is finalized. ${ }^{105}$ Subsequently, the NEB's assessment report must be finalized and a decision, in this case by the NEB, made within 365 days of the notice of commencement of the environmental assessment, subject to any requests for further information from the proponent and any extensions. The project would be allowed to proceed so long as it is unlikely to cause significant effects or, if it is, if the GIC decides that these are justified. The proponent would be required to comply with any conditions made with respect to the project and these would form part of the authorization for the project.

The process for an NEB-regulated project that does involve a certificate under section 54 also seems reasonably straightforward. It appears that this would follow the same process as with non-section 54 projects with the exception that only interested parties have the right to participate in the assessment process ${ }^{106}$ and the decision-maker is the GIC, not the NEB. As set out above, following receipt of the NEB's recommendations, the GIC can order the NEB to reconsider its decision under section 53 of the NEB Act. ${ }^{107}$

\section{Does the CANAdian ENVIRONMENTAL ASSESSMENT ACT 2012 ACHIEVE ITS OBJECTIVES?}

Various sources are available to attempt to determine the objectives of Bill C-38 and, with the debate still ongoing, further objectives, or at least different expressions of them, appear

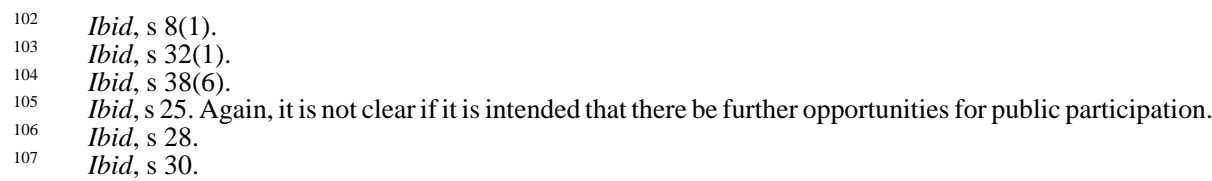


to be added on an ongoing basis. ${ }^{108}$ The title of this section should not be taken as suggesting that a determination has been made that CEAA 2012 achieves few, if any, of these objectives. Rather, it is meant to highlight that, in the space available, not all of these can be considered. As a result, this article focuses on two potential measures of the government's objectives and then considers a subset of these in assessing whether CEAA 2012 achieves these.

The two measures of the objectives of CEAA 2012 referred to in this section are the report of the Standing Committee that was released in March $2012^{109}$ and a review of the purposes of CEAA 2012, as compared to the purposes in the repealed CEAA, to determine what, if any, changes to the objectives or purposes have been made. ${ }^{110}$

The Standing Committee made 20 recommendations that, in the opinion of the majority of the Committee, would improve CEAA. ${ }^{111}$ These recommendations formed part of a broader discussion that was set out under two main themes and a number of subthemes:

\section{(1) Improving Efficiency}

(a) Improve Timelines

(b) Decrease Duplication and Target Significant Projects

(c) Aboriginal Consultation

(2) Improving Outcomes: Filling the Gaps

(a) Ensuring Early Application of the Act

(b) Positive Environmental Aspects of Projects

(c) Economic Analysis of Projects

(d) Learn from Past Assessments to Improve Future Assessments ${ }^{112}$

A full discussion of these topics is beyond the scope of this article. ${ }^{113}$ While various complaints were made about the Committee's proceedings, a review of the Standing

Some of these objectives, that have been mentioned outside of the Parliamentary process, include: ensuring Canada's ability to compete in world markets, promoting investment in the resource sector in Canada, creation of jobs, improved environmental outcomes, etc. Of course, some of these may not be taken into account by the courts in interpreting the Act if they do not form part of the record of the official passage of the Bill. See Statutory Review, supra note 7. See CEAA, supra note 3, s 4(1) as compared to CEAA 2012, supra note 4, s 4(1).

As indicated above, the Standing Committee did not actually recommend the repeal of $C E A A$, but instead recommended amendments. This likely reflects its mandate to conduct a statutory review of CEAA, rather than a replacement.

113 Interested readers are encouraged to read the whole of the Statutory Review for a better understanding of these topics, including the political discussion around the Committee's proceedings referred to in the dissenting reports. 
Committee's report provides, for the purposes of this article, a virtual roadmap to the changes to CEAA in CEAA 2012, making it a clear marker for the federal government's aspirations. ${ }^{114}$

A review and comparison of the purposes of CEAA and CEAA 2012 shows the two statutes reflect at least some of these same themes. The purposes of the repealed $C E A A$ read as follows:

The purposes of this Act are

(a) to ensure that projects are considered in a careful and precautionary manner before federal authorities take action in connection with them, in order to ensure that such projects do not cause significant adverse environmental effects;

(b) to encourage responsible authorities to take actions that promote sustainable development and thereby achieve or maintain a healthy environment and a healthy economy;

(b.1) to ensure that responsible authorities carry out their responsibilities in a coordinated manner with a view to eliminating unnecessary duplication in the environmental assessment process;

(b.2) to promote cooperation and coordinated action between federal and provincial governments with respect to environmental assessment processes for projects;

(b.3) to promote communication and cooperation between responsible authorities and Aboriginal peoples with respect to environmental assessment;

(c) to ensure that projects that are to be carried out in Canada or on federal lands do not cause significant adverse environmental effects outside the jurisdictions in which the projects are carried out; and

(d) to ensure that there be opportunities for timely and meaningful public participation throughout the environmental assessment process. ${ }^{115}$

In comparison, the new purposes of CEAA 2012 read:

The purposes of this Act are

(a) to protect the components of the environment that are within the legislative authority of Parliament from significant adverse environmental effects caused by a designated project;

(b) to ensure that designated projects that require the exercise of a power or performance of a duty or function by a federal authority under any Act of Parliament other than this Act to be carried out, are considered in a careful and precautionary manner to avoid significant adverse environmental effects;

As will be discussed below, the Standing Committee made 20 separate recommendations, the vast majority of which appear to have been adopted in the new legislation. 
(c) to promote cooperation and coordinated action between federal and provincial governments with respect to environmental assessments;

(d) to promote communication and cooperation with aboriginal peoples with respect to environmental assessments;

(e) to ensure that opportunities are provided for meaningful public participation during an environmental assessment;

to ensure that an environmental assessment is completed in a timely manner;

(g) to ensure that projects, as defined in section 66, that are to be carried out on federal lands, or those that are outside Canada and that are to be carried out or financially supported by a federal authority, are considered in a careful and precautionary manner to avoid significant adverse environmental effects;

(h) to encourage federal authorities to take actions that promote sustainable development in order to achieve or maintain a healthy environment and a healthy economy; and

(i) to encourage the study of the cumulative effects of physical activities in a region and the consideration of those study results in environmental assessments. ${ }^{116}$

While clearly subjective, after taking into account wording changes that appear to simply reflect general changes to the structure and wording of the new Act, it would appear that the three primary changes to the purposes of CEAA 2012 from CEAA are those set out in italics: (1) the primary focus on "federal" aspects of the environment; (2) the emphasis on environmental assessments being completed in a timely manner; and (3) encouraging the regional study of cumulative effects and the consideration of those results in subsequent environmental assessments.

Based on the above, and the lack of any clear overarching themes between the Standing Committee report and the revised purposes, other than the timeliness of federal environmental assessments, the discussion on whether the new Act might achieve its objectives is focused on the two primary, and potentially conflicting, themes of the Standing Committee report: improving efficiency and improving outcomes. The themes of Aboriginal involvement, stakeholder participation, and politics will be addressed in the next section.

\section{IMPROVING EFFICIENCY}

It is difficult to parse CEAA 2012 to separate out those aspects that appear to be intended to improve the efficiency of the federal environmental assessment process from other elements since many, if not most, of the changes in the Act seem directed at this goal. This is not surprising; while the Committee's goals of improving efficiency and improving outcomes are not necessarily mutually exclusive, 17 of the Committee's 20 recommendations 
were made under the heading of improving efficiency, while only three were made under the heading of improving outcomes.

Of the 17 recommendations relating to improving efficiency, a review of CEAA 2012 suggests that at least 11 of these recommendations were expressly adopted in the Act, some with further refinements. Further, in some respects the remaining six could reasonably be characterized as issues that could be addressed through the ongoing administration of the Act, rather than necessarily requiring express statutory provisions. For these remaining recommendations, there appears to be adequate flexibility under the new Act to operationalize the Committee's recommendations. As a result, assuming that the majority of the Committee's recommendations relating to improved efficiency would, at least directionally, improve the efficiency of the federal environmental assessment process, CEAA 2012 certainly appears to set the stage for doing so.

Notwithstanding this general conclusion, it may be of some concern that there do not appear to be any express provisions in CEAA 2012 addressing the Committee's recommendations on Aboriginal consultation and the coordination of Aboriginal consultation efforts with the environmental assessment process. ${ }^{117}$ While, as indicated, the intent may be to attempt to operationalize these issues and address them in the ongoing administration of the new Act, the fact that these recommendations were not addressed at any level in the Act may be a missed opportunity and result in increased uncertainty. This issue is discussed further below.

At a more subjective level, many of the changes in CEAA 2012 do appear to offer the hope for improved efficiency in the federal process beyond the simple measure of adopting the Committee's recommendations. In particular, the change to a designated list of projects, the identification of a clearly defined starting point for the federal process and a limited suite of responsible authorities, the removal of unnecessary steps in the process, and the codification of binding timelines all have the potential to improve efficiency — even without considering the potential further benefits of better coordination or reduced duplication with other jurisdictions’ processes.

However, for at least some of these efforts, the proof will be in the proverbial pudding. For instance, CEAA 2012 generally seems to be based on the premise that virtually all of the required information concerning a designated project will be in place at the beginning of the federal process; that is, while CEAA 2012 excludes the time required for a proponent to respond to requests for further information, presumably these periods are not supposed to add substantially to the time taken to review a project. However, aside from indicating that the requirements of a project description report will be set out by regulation, CEAA 2012 does not provide any guidance on how the overall goal of improved timelines will be achieved from this perspective. It would appear difficult to incorporate all of the information

See Statutory Review, supra note 7. Recommendation 15 reads: "The Committee recommends that the federal government modify its environmental assessment process to better incorporate, coordinate and streamline Aboriginal consultation during the environmental assessment process" (ibid at 19). Recommendation 16 reads: "The Committee recommends that the federal government work with Aboriginal groups, the provinces, and the territories to define the roles and responsibilities of parties in consultation, and to outline the consultation process in general. The end result should be a single consultation process that minimizes duplication” (ibid). 
requirements necessary to assess the individual characteristics of any given major energy project into regulations. Given this, how is this information intended to be identified? Is the identification of this information intended to be done through informal discussions with the relevant authorities - and presumably federal subject matter experts — prior to the filing of a project description so that the majority of the necessary studies and informationgathering can take place prior to this time? If so, CEAA 2012 does not appear to recognize a formal role for relevant agencies or other federal agencies prior to a project description being filed. In this circumstance, how will a project proponent know exactly what studies should be undertaken and how to do so? Will the Agency, other relevant authorities and, importantly, expert federal authorities be prepared to engage with proponents prior to filing a project description? If so, what faith can proponents put in these interactions if these are not a formal part of the process? What is to stop these authorities from changing their minds on the scope and methodology of studies, resulting in further delays and expense?

Alternatively, contrary to the assumption above, is detailed information gathering only intended to be accomplished after the filing of a project description? This seems counterintuitive since, at least in the context of Agency-led assessments, the project description is to be used to conduct the initial screening to determine whether an assessment is necessary. ${ }^{118}$ It is difficult to see how a fully informed decision could be made on this, without some level of information that goes beyond what could be set out in generic prescribed information requirements. Regardless, this may be the intent. If so, is it intended that, following the filing of the project description and confirmation that an environmental assessment will take place, the proponent, the relevant agency, the public (if appropriate), and other stakeholders will then engage in the development of terms of reference or environmental impact statement guidelines for further studies, as currently takes place in coordinated reviews for many major projects, effectively only starting the process at this point? While an appropriate level of flexibility seems to be beneficial in review processes, it also appears beneficial to provide a reasonable level of certainty in what participants in the process can expect, particularly if they have the expectation that assessments will take place within a year, more or less.

Similarly, the refinements to CEAA 2012 to encourage co-operation and reduce duplication of processes in other jurisdictions, particularly the provinces, also appear to offer more opportunities to improve efficiency than under the repealed CEAA. However, it again remains to be seen if they will do so in practice - and not raise other issues in doing so. It is one thing for a province to confirm that its environmental assessment process addresses the factors that need to be considered under CEAA 2012, and, therefore, request that its process be substituted for the federal process. However, with respect, it is another thing for a province to actually carry out an assessment that meets federal requirements. In general terms, it is probably fair to say that provincial environmental assessment officials and other agencies are used to considering matters within provincial jurisdiction, rather than federal matters. That is not to say that they could not learn to do so, but should this learning curve take place during the course of the review of a major energy project that may be subject to at least some level of opposition and, therefore, scrutiny? ${ }^{119}$ This gives rise to further

Note that even over time, after provincial officials presumably become more familiar with the assessment of federal matters, presumably they would still be less familiar with them than their federal counterparts. 
questions. What is the intended role of federal expert agencies in substituted provincial assessments, particularly when those agencies may subsequently have to grant federal permits after the provincial assessment is completed? What happens if a province delivers an assessment report to the federal Minister for a decision if that report, arguably, does not adequately address the federal matters required? Does the Minister sign off on the report and risk judicial review, or does he or she send the matter back to the province? Does this process improve efficiency? Can the federal government legally exempt projects that would otherwise be subject to CEAA 2012? If so, does the federal government still have a duty to consult Aboriginal peoples under this alternative or can they download this constitutional obligation to a province?

These questions are not meant to suggest that efforts to reduce duplication should not take place or that the provisions in CEAA 2012 that provide opportunities to do so are not positive. Rather, they are meant to suggest that there are complex legal, technical, and practical issues associated with these efforts and, even if duplication can be said to be reduced - "one project, one assessment" as it is described - this will not in and of itself lead to more efficient, more timely, or less risky processes.

In summary, CEAA 2012 appears to have made some positive strides in setting the stage for improving the efficiency of the federal environmental assessment process; however, ultimately the devil will be in the details and, in all likelihood, those details will be closely watched by others.

\section{E. IMPROVING OUTCOMES}

As indicated, the Standing Committee made three recommendations under the heading of Improving Outcomes, although, to be fair, they also saw potential benefits to improving outcomes from a number of their other recommendations. Recommendation 18 suggested that $C E A A$ be amended to include a consideration of potential positive environmental effects of a project. ${ }^{120}$ Recommendation 19 suggested that the federal government "explore means of ensuring follow-up programs are being implemented effectively and making information from such programs accessible to inform future environmental assessments."121 Finally, Recommendation 20 suggested that the federal government study alternative approaches for ensuring conditions from environmental assessments are enforceable and subsequently introduce statutory changes to implement its conclusions. ${ }^{122}$

There is no express adoption of Recommendation 18 in CEAA 2012, although it is clear that a responsible authority can rely on any information that is available to it in performing its assessment. It may be that it was intended that this information would be part of what is captured, and therefore required, in the regulations setting out the information required to be provided in a project description. ${ }^{123}$ However, even if this is the case, it is not clear what the purpose of it is. While the environmental assessment itself is concerned simply with the environmental effects of a project, positive or negative, the focus of the subsequent decision, 
at least in the first instance, is on the potentially significant adverse environmental effects of a project. Therefore, if it is intended that information on the potential positive environmental effects of a project should be collected, it is not clear what this information would be used for. It may be that this information could be used as part of the justification analysis if a project is found to have significant adverse effects, but there is nothing to expressly indicate this. This issue of the justification analysis is discussed further below.

In contrast, the federal government clearly adopted the essence of the Committee's recommendations on follow-up programs and the enforceability of project conditions, if not going one step further. The Committee recommended that the government study approaches for ensuring that conditions from environmental assessments are enforceable and that the government subsequently introduce changes to CEAA to accomplish this. Rather than carrying out this study, at least over any extended time, CEAA 2012 simply makes the carrying out of project conditions enforceable by various means.

What is not clear under CEAA 2012 is how information from follow-up programs will be made available to proponents and participants in other environmental assessment processes, which was one of the concerns and suggestions that gave rise to this recommendation. Ensuring that follow-up programs are put in place and followed, and, where necessary, adaptive management measures are put in place to attempt to mitigate unanticipated adverse effects, clearly has the potential to improve outcomes. However, making information available on the success of previous mitigation measures, or lack thereof, appears to have the potential to both magnify this positive outcome and to reduce the costs of other proponents and processes attempting to develop mitigative measures on an ad hoc basis in the absence of information on what has been done before.

Speculating on whether Bill C-38 will actually improve environmental outcomes quickly moves beyond the realm of lawyers. However, from a legal and process-oriented perspective, it appears that a couple of observations on the prospect of Bill C-38 actually improving outcomes are reasonably justified.

First, as noted above, there is an obvious tension between improving efficiency and improving outcomes. Care will have to be taken to ensure that, as steps are put in place to improve timelines and reduce duplication, the effectiveness and compliance with the other purposes of CEAA 2012 does not suffer. Ultimately, judges will make the final decision regarding whether a process complied with all of the purposes and requirements of the Act.

Second, while admittedly after the fact, the requirement for transparent and enforceable follow-up programs and project conditions - again if treated in accordance with all of the purposes of the new Act — should, in and of itself, encourage standards to be maintained and improved throughout the process. Follow-up programs can be expensive; however, they can be even more expensive if adaptive management measures are required to be put in place to address negative effects that were not anticipated because of a failure at some point in the assessment and decision-making process. Accordingly, in theory at least, the requirement for follow-up programs and enforceable conditions has the potential to provide both for better outcomes and some check on the efficiency-related goals otherwise overwhelming the other purposes of the new Act. 


\section{How does the CANAdian ENVIRONMENTAL ASSESSment ACt 2012 AdDress ABoriginal, STAKEHOLdER, AND Political IsSUES?}

\section{A. INTRODUCTION}

As indicated above, the original purpose of this article was to examine the role of Aboriginal, stakeholder, and political influences both within and outside of existing energy project approval processes. It was then proposed to examine the capability of existing processes to address these issues and, to the extent that it appeared that existing processes are not adequate to do so, what might be done to enhance or amend these processes. This task, interrupted by Bill C-38, will be returned to in the last section of this article.

In the meantime, it seems worthwhile to consider how CEAA 2012 addresses these issues. There are few, if any, major energy projects that have been through federal environmental assessment processes recently that have not experienced one or more of these influences, at least resulting in delays and increased costs.

\section{B. Aboriginal Issues}

Aboriginal issues in Canada do not need an introduction. On any given day, it is unusual if there is not some story in the media concerning the intersection of Aboriginal interests and resource development. A number of these stories are about court challenges.

As most people are aware, Aboriginal issues are ultimately legal issues, and, therefore, give rise to legal risks. Any time that the federal government, or a provincial government, makes a decision that has the potential to affect established or asserted Aboriginal rights, it has a duty to consult, and potentially accommodate, the Aboriginal group in question. ${ }^{124}$ While the Crown can delegate certain aspects of this duty to third parties, such as project proponents, the Crown must retain the final responsibility for ensuring that the duty is met. ${ }^{125}$

In most instances, a finding that there has not been adequate consultation results in an order that further consultation take place. However, there is a risk that an approval could be set aside. Regardless, whether or not adequate consultation has taken place, regulatory and legal proceedings to determine the adequacy of consultation can take substantial periods of time, and post-approval legal challenges can further delay project approvals and the commencement of construction.

As indicated above, apparently in express recognition of this issue, the Standing Committee recommended that the federal government modify the environmental assessment process under $C E A A$ to better incorporate, coordinate, and streamline Aboriginal consultation decisions will attract a duty to consult notwithstanding modern land claim settlements (see e.g. Beckmann v Little Salmon/Carmacks First Nation, 2010 SCC 53, [2010] 3 SCR 103), there will also be some instances where common law consultation beyond the provisions of a land claim agreement will not be required. 
during the environmental assessment process. ${ }^{126}$ The Committee further recommended that the federal government work with Aboriginal groups, the provinces, and the territories to define the roles and responsibilities of parties in consultation, and to outline the consultation process in general. According to the Committee, the end result should be a single consultation process that minimizes duplication. ${ }^{127}$

There is nothing in CEAA 2012 that expressly addresses the first issue, although, as indicated, it may be that this was intended to be addressed through administrative measures. Minister Oliver, the federal Minister of Finance, has indicated on more than one occasion since the introduction of Bill C-38 that the federal government is committed to providing more money to Aboriginal groups to participate in project review processes. ${ }^{128}$

The second recommendation, that the federal government, Aboriginal groups, provinces, and the territories work together to attempt to arrive at a single consultation process, is admittedly forward-looking - and unreasonable to expect to be captured in Bill C-38. However, in other instances the federal government did take steps beyond the Standing Committee's recommendations. This raises the question of whether there are more things that could have been done on this issue in Bill C-38.

The consideration of Aboriginal interests as part of major energy projects is not new. As only one example, in 1977, even before Aboriginal rights were recognized in the Constitution Act, 1982, ${ }^{129}$ Justice Thomas Berger recommended that the then proposed Mackenzie Valley pipeline be delayed for ten years so that land claims and other Aboriginal issues could be addressed. ${ }^{130}$ Notwithstanding this foreshadowing of the potential impact of Aboriginal issues on energy project proceedings - and energy projects themselves - until recently, there does not appear to have been any real recognition of the role of Aboriginal interests in these processes, let alone attempts to consider how to address them. ${ }^{131}$ As a result, the role of

See Recommendation 15, Statutory Review, supra note 7 at 19.

See Recommendation 16, Statutory Review, ibid.

Joe Oliver, "Notes for Remarks” (Address delivered at the World Forum on Energy Regulation, Quebec City, 14 May 2012), online: Natural Resources Canada <http://www.nrcan.gc.ca/media-room/speeches/ 2012/62/6229>.

129 Being Schedule B to the Canada Act 1982 (UK), 1982, c 11.

See Thomas R Berger, Northern Frontier, Northern Homeland: The Report of the Mackenzie Valley Pipeline Inquiry, vols 1 \& 2 (Ottawa: Minister of Supply and Services Canada, 1977).

131 In 1994, in Quebec (AG) v Canada (National Energy Board), [1994] 1 SCR 159 [Quebec Cree], the Quebec Cree appealed an NEB decision on the basis that the Board had breached a fiduciary duty to the Quebec Cree by not giving their issues priority over other interests. Ultimately, the Supreme Court of Canada rejected this argument on the basis that the NEB was a quasi-judicial body and, therefore, not in a position to place the Cree's interests ahead of other interests. However, the Court still indicated that the NEB needed to exercise its powers "constitutionally.” Unfortunately, the Court did not indicate what it meant by this. Since the Quebec Cree case, Aboriginal interests have continued to be raised in energy project approval processes from time to time but, for the most part, have generally been addressed through normal hearing processes and without fully addressing the constitutional arguments that have tested the courts on these issues. A notable exception is the Joint Review Panel process for the Mackenzie Gas Project. In that instance, the Dene Tha' First Nation alleged that they should have been consulted during the establishment of the Joint Review Panel process. In Dene Tha' First Nation $v$ Canada (Minister of Environment), 2006 FC 1354, 303 FTR 106, aff'd Canada (Minister of Environment) v Imperial Oil Resources Ventures Ltd, 2008 FCA 20, 35 CELR (3d) 1, Justice Phelan accepted the Dene Tha's arguments and found that, since the Joint Review Panel would eventually make a decision that could affect the Dene Tha's rights, they were entitled to be consulted on this step in the process. Notwithstanding that the federal government subsequently reached a settlement with the Dene Tha', the parties agreed that the appeal of Justice Phelan's order would still be heard by the Federal Court of Appeal. While the Federal Court of Appeal indicated that it did not necessarily agree with all of Justice Phelan's comments in coming to his conclusion, it still upheld Justice Phelan's decision. 
Aboriginal interests in energy project approval processes seems to be developing on an ad hoc basis, mostly as a result of obligations being judicially superimposed on existing structures, rather than in a considered and forward-looking manner. In this context, the Standing Committee's recommendation that the federal government, Aboriginal groups, provinces, and the territories work together to attempt to arrive at a coherent consultation process for major projects seems welcome. However, further efforts that could address some of these issues in the short-term could be desirable while the federal government pursues this initiative.

As some readers will be aware, there has now been judicial guidance from the Supreme Court of Canada on the role of administrative bodies in the Crown's consultation efforts in Rio Tinto Alcan v. Carrier Sekani Tribal Council. ${ }^{132}$ In Rio Tinto, the Supreme Court confirmed that administrative tribunals are creatures of statute and, notwithstanding the constitutional undertones of Aboriginal law obligations, these tribunals still only have those powers that have either been expressly or implicitly conferred on them. ${ }^{133}$

In establishing an administrative tribunal or decision-maker, a government may choose to delegate the duty to consult, the power to determine whether adequate consultation has taken place, both of these, or neither. ${ }^{134}$ Ultimately, what was intended is a question of statutory interpretation to be decided based on an examination of the decision-maker's power to decide questions of law and their remedial powers. ${ }^{135}$ Given that this is a question of statutory interpretation, what is the role of various parties in carrying out and assessing the duty to consult under CEAA 2012? Or, in other words, given the guidance in Rio Tinto, has there been anything done in CEAA 2012 to attempt to reduce the uncertainty, and therefore risk, associated with this question?

In terms of an express grant, there does not appear to be anything in CEAA 2012 that achieves this purpose (for example, an express indication of what the role of the various entities is in the consultation and accommodation process). There are four express references to Aboriginal people in CEAA 2012: (1) in the purposes section (as already mentioned, "to promote communication and cooperation with aboriginal peoples with respect to environmental assessments”); ${ }^{136}$ (2) in the list of Federal matters to be assessed; ${ }^{137}$ (3) in the ability to take into account community knowledge and Aboriginal traditional knowledge in conducting assessments; ${ }^{138}$ and interestingly, (4) in the Agency's objects, specifying that the Agency is to "engage in consultation with Aboriginal peoples on policy issues related to this Act." 139 None of these - or anything else in CEAA 2012 — appears to provide an express answer to the question of who, if anyone, is responsible for what in carrying out or assessing the duty to consult in relation to federal environmental assessments. To the contrary, how will this question be answered when the issue comes before the courts, given that the Agency is given the express power and obligation to engage in consultation with Aboriginal peoples

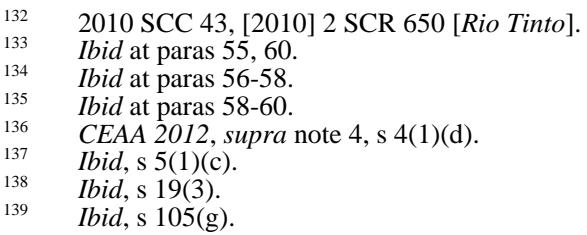


on policy issues related to the new Act? Does the express inclusion of this topic suggest that the Agency was not intended to have any other role regarding consultation (expressio unius est exclusio alterius)?

If there is no express answer to this question in CEAA 2012, what can be implied? The Supreme Court has indicated that the currently identified considerations to inform this inquiry are the power of the decision-maker to decide questions of law and his, her, or its remedial powers. A review of CEAA 2012 suggests that neither the Agency, review panels, the Minister, nor the GIC have the express power to answer questions of law. ${ }^{140}$ It further suggests that the answer to the question regarding each of these entities' remedial powers is equally unclear. Most of these entities' powers are expressed in terms of carrying out the environmental assessment and the decision-making process themselves, not in the context of remedial powers. While there are some powers that can be directed at the proponent, such as the need to provide further information or the power to impose a follow-up program and conditions, are these enough — or even relevant - to persuade a court of what the statutorily-granted role of these bodies is in respect of consultation? ${ }^{141}$

For some of these bodies, it seems fairly obvious what their role in the consultation process should be. However, the Supreme Court did not say that this answer should be based on intuition; rather, this needs to be based on the wording of the statute, and the statute seems, at best, unclear. As indicated, experience shows that uncertainty in this area means delay and legal risk. Given the federal government's express objective of reducing delays associated with major project approval processes, it would appear that one useful enhancement to CEAA 2012 would be to address the threshold question of what role each of the various entities in the federal environmental assessment process are intended to play in consultation. Are they intended to consult with Aboriginal groups? Are they intended to assess the adequacy of consultation? Both? Neither? An express answer to these questions would go the furthest in providing legal certainty. However, even clarification on the considerations currently identified by the Supreme Court would appear to be helpful. ${ }^{142}$

Without wanting to be pedantic on this issue, what about project proponents? What is their role, if any, in fulfiling the duty to consult? Most project proponents go to significant lengths to attempt to consult with Aboriginal groups, and the courts have confirmed that it is open to government to delegate aspects of this duty to third parties. However, CEAA 2012 does not address this issue. Are efforts by project proponents intended to be used to attempt to satisfy the duty to consult under CEAA 2012? If so, how are these obligations to be delegated, who has the power to do so, and when does this take place? If the federal government has no official role under CEAA 2012 until a project description is filed, what is the legal status of the consultation efforts that take place before this point in time? Can the CEAA 2012), but none of these appear to extend to deciding questions of law.

141 Note that for some responsible authorities other than the Agency, these answers are much clearer. For example, the NEB has the power to decide questions of law (see section 12(2) of the NEB Act, supra note 36) and also has remedial powers similar in nature to the powers of the British Columbia Utilities Commission at issue in Rio Tinto.

142 Note that, notwithstanding the comment above about the answer to these questions being clearer for some responsible authorities such as the NEB, this does not mean that the answer could not be made even more express and further reduce legal uncertainty and potential risks. 
federal government rely on them? Does it have the power to effectively retroactively grant authority to carry out aspects of the duty to consult? Again, clarification on these issues would appear to be beneficial.

Numerous additional questions could be asked on this topic, but the short answer appears to be the same to each of these: CEAA 2012 does not directly address Aboriginal issues. There may be good reasons for this. It is clearly difficult for statutory provisions to keep pace with rapidly developing areas of the law. It also has not been conclusively settled whether governments owe a duty to consult on new legislation, potentially complicating attempts to even address these issues. ${ }^{143}$ However, as indicated, legal uncertainty in this area translates directly into delay and legal risks and there do appear to be certain threshold questions that could be answered to reduce the level of legal uncertainty, at least somewhat. Further thoughts on this topic from a broader perspective are provided in the last section of this article.

\section{Stakeholders, Policy, and Politics}

Unlike Aboriginal interests, private stakeholders always seemed to have played some role in major energy project review processes. This is not particularly surprising; administrative law principles confirming an individual's right to be heard before a decision is made that would affect their interests have been in place for a longer period of time than Aboriginal obligations. These principles may also be better understood than developing principles of Aboriginal law. While it is impossible to deconstruct the substantive basis for stakeholder participation from the legal requirement to do so, it also appears to be generally accepted that at least some stakeholder interests deserve to be considered as part of the public interest test that many energy approval processes are centred on. As a result, many of Canada's energy project review processes have express requirements addressing the role of the public and parties who may be directly affected by an energy project.

Given this general acceptance of the legitimacy of stakeholder participation, why is it that public participation in energy review processes seems to be controversial? What prompted the federal Minister of Natural Resources, in his recent Open Letter, to label certain interveners in the Northern Gateway process "radical groups" who are trying to "hijack our regulatory system”144 if they are simply trying to express legitimate views? Conversely, if interveners are allowed to express their views in these proceedings, why does it appear that there is so little acceptance of regulatory decisions and that so much of the debate over energy project approvals occur outside of these processes?

This part of the article examines the issue of stakeholder engagement in the context of Bill C-38. It also examines the potential impact of Bill C-38 on policy and politics. While, in theory, these are different topics, there appear to be significant overlaps in the context of energy project review processes and, as the debate between stakeholder interests, policy, and

The Supreme Court of Canada expressly left this question for another day in Rio Tinto, supra note 132 at para 44 .

Natural Resources Canada, News Release, “An Open Letter from Minister Oliver on Our Energy Markets and the Regulatory Process” (9 January 2012), online: Natural Resources Canada <http://www. nrcan.gc.ca/media-room/news-release/2012/1/3525> [Open Letter]. 
politics unfolds, it appears to be touching on both pillars of procedural fairness: audi alteram partem (the right to be heard) and nemo judex in sua propria causa debet esse (no one should be a judge in her or his own cause). Accordingly, both of these topics are considered together.

While perhaps not completely necessary to understand the legal effects of CEAA 2012 from these perspectives, some further discussion of the events leading up to Bill C-38 may help illustrate some of the specific concerns about the participation of stakeholders in federal environmental assessment processes that gave rise to the provisions directed at this issue.

Oliver's reaction in his Open Letter seemed to be a direct response to the level and nature of stakeholder involvement in the review process for the Northern Gateway project. Leading up to the beginning of the Northern Gateway hearing, over 4,000 individuals had registered to make submissions on the project - some of these from outside of Canada. Not surprisingly, it was estimated that these submissions would take months to hear.

In response, Oliver issued his Open Letter on the eve of the hearing. Digging beneath Oliver's more provocative characterizations, he appears to have two substantive concerns. The first appears to be policy-oriented. As expressed in the Minister's letter: "For our government, the choice is clear: we need to diversify our markets in order to create jobs and economic growth for Canadians across this country. We must expand our trade with the fast growing Asian economies. We know that increasing trade will help ensure the financial security of Canadians and their families." ${ }^{445}$ Oliver then expresses his first concern: "Unfortunately, there are environmental and other radical groups that would seek to block this opportunity to diversify our trade. Their goal is to stop any major project no matter what the cost to Canadian families in lost jobs and economic growth. No forestry. No mining. No oil. No gas. No more hydro-electric dams."146

While Oliver's comments may have been intended to go even further than this, at a minimum he appears to be concerned that project approval processes are being used to debate what he considers to be established federal government policy — which is not intended to be part of the hearing process.

Oliver's second concern is focused on a specific issue. According to Oliver, project opponents are "stacking public hearings with bodies to ensure that delays kill good projects." 147 There appears to be some room for debate about where discussion on government policy issues should take place. However, there is less room for debate over Oliver's second concern: if project opponents are attempting to use project review processes to cause delays that could prevent a project from proceeding, there does not appear to be any reasonable justification for this.

The next section of this article will compare the new Act with the Minister's concerns to determine whether CEAA 2012 appears to address these concerns and, if so, whether it's 
likely to succeed in doing so. While this is a new measure of the potential success of CEAA 2012 in meeting its goals, it appears appropriate given Oliver's strong feelings about these issues. The Standing Committee's recommendations and the revised purposes in CEAA2012 will also be discussed where appropriate.

As indicated, Oliver's first concern appears to be centered on interveners attempting to debate what is considered to be established government policy during Northern Gateway-like processes. Oliver's specific concern was with people expressing support for a broad nodevelopment approach as an alternative to the federal government's preference for building new infrastructure in order to diversify existing markets. However, this can easily be extrapolated to other situations where the review processes for individual projects become a potential forum for broader policy issues.

The primary step that appears to have been taken in CEAA 2012 to address this concern is amending the factors that need to be considered in carrying out an environmental assessment. Under CEAA, the responsible authority and the Minister had the express power to require that an environmental assessment consider the need for and alternatives to a project. ${ }^{148}$ Under CEAA 2012, while the relevant authority and the Minister still have the discretion to require that additional factors be considered, the express reference to need and alternatives has been deleted. ${ }^{149}$ This suggests a shift from a predisposition to include this factor in recent assessments to one of not doing so. As discussed below, the need for a project can be closely aligned with broad government policy. Accordingly, removing the considerations of need and alternatives from the scope of an assessment is likely to further distance the review process from government policy, presumably allowing attempted debates over larger government policy issues to be determined to be beyond the scope of the process. It may be that the narrowing of the interests to be assessed in section 5 of CEAA 2012 was also intended to attempt to avoid debates on broader policy issues taking place during assessment processes. By focusing the environmental assessment on certain identified heads of federal power, this could further narrow and define the scope of the proceeding.

Oliver's second concern was that some people appeared to be trying to use the Northern Gateway process itself — and presumably other review processes - to delay and, ultimately, to stop projects from taking place. In particular, given the number of people who registered to speak at the Northern Gateway hearings, Oliver was concerned that opponents were stacking the hearings to achieve this objective. The goal of these tactics is, of course, to delay the process for long enough that either the political will behind the project evaporates or the project no longer makes commercial sense.

It appears that the primary mechanism in CEAA 2012 that is intended to address this issue is narrowing who gets to formally participate in certain types of assessments. While some Agency-led assessments still provide for the participation of the public at large, it would appear that for what are generally the more significant projects — review panel projects and 
NEB section 54 applications - only interested parties have the right to participate in the formal hearing processes. ${ }^{150}$

Under CEAA, there was no a formal test for who had standing before review panels. Therefore, under the new Act, it appears that there will be less people who qualify to formally participate than there were previously and, therefore, based purely on numbers, less opportunity for delay. There is currently a limit on who can formally object to an application for a certificate under section 54 of the NEB Act, which is replicated in CEAA 2012. ${ }^{151}$ Accordingly, it is not clear if these measures will reduce the number of participants in section 54 proceedings. It is not clear whether this limit has generally been applied when the NEB was part of a joint review panel. If it has not been, it appears that there may be some opportunities to reduce the number of formal participants in certain NEB hearings from what would have occurred in the past.

Based on the above, it appears that steps were taken in Bill C-38 to both limit the public debate over matters of federal policy and to avoid hearing-stacking. Once again, only time will tell whether these tools will be effective. Scoping the need and alternatives to a project out of an assessment certainly has the potential to reduce submissions on policy issues that are outside of the scope of the process. However, there is still some level of risk associated with this method since any submission that is close to the line in terms of scope raises a risk that a court of appeal will disagree with the relevant authority's scoping decision and re-open the hearing so that these matters can be considered.

It appears that putting in place provisions in CEAA 2012 to attempt to limit the number of participants in formal hearings may not achieve its desired objective. As discussed, this measure appears to be primarily directed at reducing the potential for delays through hearingstacking. However, in assessing whether this will reduce the length of new processes, new review processes will now have to take additional time to hear submissions and make determinations on who is an interested party. Let us say that 4,500 people apply for interested party status in a review panel proceeding. If each of these people takes ten minutes to tell the review panel why they should qualify as an interested party, or it takes the review panel ten minutes to read the average written submission on this issue, that totals 45,000 minutes or around 750 hearing hours. This would take approximately 75 additional 12 hour long hearing days, ${ }^{152}$ or approximately four months, ${ }^{153}$ to accomplish this new task.

Perhaps more significantly, determining who is an interested party involves risk. As indicated, under CEAA 2012 a person qualifies as an interested party based on three criteria: (1) they will be directly affected by the carrying out of the project; (2) in the review panel's opinion they have some relevant information to provide; and (3) they have expertise related to the project, again in the review panel's opinion. ${ }^{154}$ While who is directly affected by a

Ibid, s 24. Note that if the carrying out of the designated project requires that a certificate be issued under section 54 of the NEB Act, supra note 36, the NEB is only required to ensure that any "interested party" has the opportunity to participate. Including time for breaks.

A more realistic estimate is probably closer to six months. This would allow for one week off per month and would also allow time for the hearing to move to different locations, if necessary.

CEAA 2012, supra note 4, ss 2(1)-(2). 
project or activity is the subject of existing jurisprudence under other legislation, and appears to be reasonably well understood, the other criteria are new and do not appear to have been considered by the courts. ${ }^{155}$

Going back to our example, let us say that after the review panel spends its 750 hours of hearing time listening to the 4,500 people who applied for interested party status, and then a further amount of time making determinations and writing decisions on these applications, it finds that 100 people qualify for interested party status and the other 4,400 do not. What is the chance that none of these 4,400 people will be successful in convincing a court of appeal that the review panel erred in its determination of their status? In Alberta over the last five years, 13 appeals have been brought on the issue of whether a party was "directly affected" by a proposed development - a common test of standing in Alberta and, as indicated, one of the potential criteria that would allow a person to be an interested party. ${ }^{156}$ Of these, only two appeals were successful. ${ }^{157}$ While this may seem like a good track record, if this percentage were applied to the 4,400 people appealing their denial of interested party status, this suggests that just over 700 of them would subsequently be granted standing by a court of appeal.

Of course, the margin for error in any given process would almost certainly be different — less or more — than what has been experienced in the past. ${ }^{158}$ However, the absolute numbers, ultimately, do not appear to matter. The review panel only needs to have been found to have erred for one person on one part of the interested party test for there to be a risk that the assessment process could be re-opened, potentially long after it was otherwise completed. This appears to suggest that the federal government's proposed limitations on who can participate in certain proceedings may not be as helpful in reducing the risks of delays as it appears intended.

What about policy and politics? These are both issues that the federal government has expressed concerns about. What measures appear to be built into CEAA2012 to address these issues? To some extent, the issue of policy has already been discussed. As indicated, by reducing the scope of the issues to be considered in federal assessments, it appears that the federal government is hoping to avoid policy level issues that the government considers to be outside the scope of the assessment at issue.

Another tool that appears to be directed at this concern is a clearer definition of the responsibilities of various parties during the assessment and decision-making process. In general, this appears to have been addressed by assigning the responsibility for carrying out an environmental assessment and making the subsequent determination of whether a project is likely to cause significant adverse effects to the relevant authority (except in the case of [unpublished].

156 See e.g. Environmental Protection and Enhancement Act, RSA 2000, c E-12, s 44(6); Energy Resources Conservation Act, RSA 2000, c E-10, s 26(2) (directly and adversely affected).

157 See Kelly v Alberta (Energy Resources Conservation Board), 2011 ABCA 325, 515 AR 201; Kelly v Alberta (Energy Resources Conservation Board), 2009 ABCA 349, 464 AR 315.

158 Note that the margin of error above is from decisions of experienced tribunals on a test that they are familiar with. They do not involve what may be an inexperienced review panel and a new test for interested parties on which there is no jurisprudence. 
Agency assessments where the determination of significant effects is made by the Minister), but reserving the final decision-making power to the GIC on projects that are expected to cause significant effects. This does appear to have the potential to reduce confusion on who is responsible for what and form a brighter line between what might be considered technical and policy issues. It also clearly assigns responsibility for policy decisions to the federal Cabinet, which is presumably who should be making these decisions.

There do not appear to be any specific provisions in CEAA 2012 addressing politics. It may seem surprising that this is suggested as a measure of the success of CEAA 2012; however, this is an issue that the federal government has expressed concerns about in other jurisdictions. Though CEAA 2012 does not appear to be intended to address political issues directly, that does not mean that it does not give rise to issues, and potential risks, from a political perspective. The most significant of these seem to be associated with the Minister. As indicated, the Minister exercises numerous statutory powers under the new Act. Among other things, he or she can or must:

(1) Designate an otherwise undesignated project as a designated project; ${ }^{159}$

(2) Identify any additional factors that a review panel should consider during its assessment of a project; ${ }^{160}$

(3) Agree that a provincial environmental assessment process is an appropriate substitute for a federal environmental assessment; ${ }^{161}$

(4) Establish a review panel, or a joint review panel, to carry out an assessment; ${ }^{162}$ and

(5) Following an assessment, decide whether certain projects are likely to cause significant effects. ${ }^{163}$

In some of these instances, the Minister is given express guidance on the factors that he or she is to consider in making the particular decision. ${ }^{164}$ On others, there is less guidance. Regardless, this does not mean that the Minister is free to take into account anything he or she chooses. This decision-making still needs to take place within the bounds of the particular provisions and CEAA 2012 as a whole.

More significantly from a political perspective, given the Minister's statutory duties, it also appears to mean that the Minister is not entitled to be a judge in his own cause (for example, he may not want to express the view that a project is a "good project" prior to having the results of an assessment before him). Stated from a different perspective, a person whose interests will be affected by a project is entitled to have a decision-maker, such as the

CEAA 2012, supra note 4, s 14. A "designated project” is defined in section 2(1) of the Act.

Ibid, s 19(1)(j).

Ibid, s 32(1).

Ibid, s 38(1).

Ibid, s 27(1). The Minister is responsible for making this assessment for Agency assessments and for review panel assessments.

See e.g. ibid, s 14(2), which provides criteria on the considerations for designating a project as a designated project. 
Minister, who is free from any perception of bias. Accordingly, given the Minister's formal statutory role under CEAA 2012, if the Minister says or does anything of a political nature that suggests that he may not be impartial in his decision-making, any of his decisions could be set aside.

What about the views of other members of Cabinet, given the role of Cabinet in the assessment and decision-making process under the new Act? Could it be argued that the expression of other members of Cabinet's views on a proposed project or initiative taints any subsequent decision by Cabinet? In Canada (A.G.) v. Inuit Tapirisat, ${ }^{165}$ the Supreme Court of Canada held that the mere fact that a decision is made pursuant to a statutory power vested in Cabinet does not mean that it is beyond review. However, in the circumstances, the Court went on to find that Cabinet did not owe the petitioners a duty of fairness in making the decision in question. ${ }^{166}$

In potentially prescient language, the Court explained their decision as follows:

\begin{abstract}
Indeed it may be thought by some to be unusual and even counter-productive in an organized society that a carefully considered decision by an administrative agency, arrived at after a full public hearing in which many points of view have been advanced, should be susceptible of reversal by the Governor in Council. On the other hand, it is apparently the judgment of Parliament that this is an area inordinately sensitive to changing public policies and hence it has been reserved for the final application of such a policy by the executive branch of government. ${ }^{167}$
\end{abstract}

What would happen if a similar situation came before the Supreme Court of Canada under CEAA 2012? Clearly, the Cabinet would be required to observe any statutory conditions precedent to the exercise of its decision, ${ }^{168}$ but assuming that it does, does Cabinet owe a duty of impartiality prior to considering a project, or would the Supreme Court of Canada find itself repeating its language from Inuit Tapirisat to find that a decision of Cabinet under CEAA 2012 is intended to be a policy-based one and thus unappealable? On the one hand, it seems somewhat inappropriate that all members of the federal Cabinet would be prohibited from expressing any opinions on matters of government policy during the course of any energy project review process that might come before them. On the other, some of the factors that the Supreme Court of Canada took into account in Inuit Tapirisat to find that the Cabinet was insulated from review in that circumstance do not appear to be in place in CEAA 2012, raising questions about what was intended. Given the potential risks that this could give rise to, some express clarification of the intended nature of the Cabinet's role may be of some assistance. 


\section{A Broader Consideration of Aboriginal, STAKEHOLDER, AND POLITICAL ISSUES}

\section{A. INTRODUCTION}

What about the potential impact of Aboriginal, stakeholder, and political issues on energy project review processes beyond the steps that have been taken to address these issues in Bill C-38? While Bill C-38 is likely to influence aspects of the review process for many major energy projects, it is not the only review process for a number of these projects, and may not even apply to some of them. Given that it is difficult to imagine any future scenario where there will not be Aboriginal, stakeholder, and political issues associated with major energy projects, it appears worthwhile to consider what else might be done to attempt to reduce at least some of the risks and other potential impacts associated with these influences. The following section offers some thoughts from this perspective. These are by no means the only things that could be done nor, on further consideration, might they turn out to be things that should be done. However, it seems timely to begin engaging in a broader discussion about what improvements could be made in the way that we address these issues in our energy review processes, given their importance to the energy industry in Canada. ${ }^{169}$

\section{B. Aboriginal Issues}

A brief introduction to the duty to consult and accommodate was provided above. While this duty is not the only issue that gives rise to Aboriginal considerations in the context of major energy project review processes, it is the issue that can have the most significant impact on these processes.

Given that CEAA 2012 does not appear to have been intended to expressly address issues arising from the duty to consult, there has not been a lot of discussion about some of the issues that the duty raises in review processes. Rather than attempting to identify and discuss these in detail, it is probably easier to say that it is difficult to think of anything that takes place during a review process that does not give rise to potential issues associated with the duty to consult. Every step, communication, study, analysis, etc. is scrutinized for whether some argument might exist that the duty was offended, both during, and in some cases following, review processes.

Given this pervasive nature, there are no means that are going to address all of the issues that the duty to consult gives rise to. A further complication is that, because the duty encompasses everything from strategic decisions forward, the federal and provincial governments may have to actually consult on the remedial steps that they are considering taking to address issues arising out of the duty before taking these steps. ${ }^{170}$ This does not mean that these steps should not be taken, only that it may take significant time to identify and implement certain measures. 
Notwithstanding these considerations, it appears that there are some initial steps that could be taken to attempt to address some of the potential impacts of Aboriginal issues on major energy project review processes. The following discussion considers two of these issues. While not comprehensive by any means, it appears that these could be of some assistance.

The overall goal appears to be to attempt to reduce unnecessary delays and risks that arise from the duty to consult. From this perspective, the first step that could have wide-scale benefits has already been identified in the discussion of CEAA 2012. That is, taking concrete steps to define what the role of the different statutory entities in energy project review processes is in satisfying and evaluating the Crown's duty to consult. Simply raising this question during a review process can, in and of itself, take substantial time. It also creates a substantial legal risk since there is a chance that the tribunal or other entity could be wrong in their answer to this question, even if the issue is only impliedly addressed as the review process moves forward. Given that the Supreme Court of Canada does not even appear to feel that they have quite figured out the test for who has what role in the consultation process, any decision or action in this area appears to have at least some uncertainty associated with it. This suggests that it might be worth taking steps to attempt to reduce any unnecessary delays, effort, and risk raised by this issue.

The Supreme Court of Canada has now confirmed that the role of decision-makers in satisfying the duty to consult is not a constitutional add-on to the statutory regime but is a question of the interpretation of the statute in issue. ${ }^{171}$ What role, based on the statute in question, was it intended that the particular statutory entities would have regarding the duty to consult? The responsibility to carry out the duty? The responsibility to evaluate it? Both? Neither? Notwithstanding ongoing statutory amendments to many of the environmental assessment and other review process regimes in Canada, virtually none of the statutes establishing these processes expressly address which entities have what responsibility, if any, for the duty to consult. Further, like CEAA 2012, many of these statutes also do not address the factors that the Supreme Court of Canada has currently identified to help decide this question.

The easiest way to address this issue appears to be to amend these statutes to expressly indicate, for the review process in question, who has the responsibility to undertake consultation and accommodation discussions with Aboriginal groups and who has the responsibility to assess the adequacy of consultation. While it could be argued that there are benefits to maintaining some flexibility in these roles for individual assessments, a consideration of the types of entities involved and their specific roles in the statutory review process seems to suggest that there is little likelihood that these roles would shift in the context of any given review. Further, retaining this flexibility appears to simply give rise to new timing issues and duties when these roles are established for each individual review. While another means of addressing this issue would be to provide clarity in the statute on the considerations that the Supreme Court indicated were factors in its analysis, it appears that express language would be the easiest and most certain way of addressing this issue. This has the potential to remove any questions of interpretation and, in turn, avoid debates over who 
has what role in satisfying the duty to consult, and the delay and uncertainty associated with these debates. This clarification might also assist the consultation process itself.

This leaves open the question of what the role of a proponent is in consultation. Again, as indicated, the Supreme Court of Canada has confirmed that a proponent can be delegated certain aspects of the duty. ${ }^{172}$ However, a formal delegation does not always take place as part of review processes and, even if it does, it is not always clear whether the entity purporting to make this delegation has the power to do so. Almost all review processes today rely heavily on consultation undertaken by the proponent. Given this, it appears that it might also be a good idea to address these issues. Any provisions addressing delegation should probably also take into account that many proponents engage with Aboriginal groups early in the project development process before doing almost anything else on a potential project. Accordingly, in theory, the delegation should be in place at this time, reasonably soon thereafter, or at least address any timing issues.

Finally, can something be done to clarify who is to be consulted $?^{173}$ While this is clear in most cases, where it is not, this can be a particularly vexing issue and one that can again create significant risks of delay and uncertainty. One of the primary reasons that there is uncertainty and risk associated with this issue appears to be that the question of who should be consulted with is generally left to be determined after the end of the review process. This gives rise to a risk that substantial portions of the consultation process, and the statutory review processes, will have to be redone if it is subsequently determined that the wrong group was consulted with, or that an additional group should have been consulted with. What if there was a step that was inserted during the early stages of review processes to address any questions about who should be consulted within any given Aboriginal group? While this would not avoid the risk of subsequent legal challenges, it would at least require any challenges to start, and presumably end, sooner, in theory reducing the potential consequences of an adverse outcome. ${ }^{174}$ It may also give legitimacy to consultation with alternative groups through the period that this issue is being resolved, which is something that can otherwise be difficult to achieve in practice, thereby further reducing these risks and encourage alternative resolutions of these issues.

A second broad topic that appears worthwhile to discuss is the time that it takes to undertake consultation and the various disagreements that arise between the parties during the consultation and statutory review processes. ${ }^{175}$ These issues are at the core of the potential impacts of the duty to consult, causing delays and giving rise to uncertainty.

172 See Haida, supra note 124.

173 Note that this question is referring to who, within an Aboriginal group, is responsible for consultation, not which Aboriginal groups are to be consulted with.

174 An additional aspect that could assist with this issue would be to place time limits on the time for filing judicial review applications. Many challenges to determinations involving Aboriginal issues are currently brought by judicial review. However, many judicial review statutes in Canada do not currently have time limits within which a judicial review must be sought. It does not appear unreasonable to establish a time limit for judicial reviews to compel a party who does not agree with a particular decision to move the issue forward in a timely fashion.

175 A “disagreement" in this context is defined as anything that agreement is not reached on. Any time that an agreement is not reached, the legal risks are raised. 
Good consultation does take time and there will also be times when the parties will not agree. However, there are also often unnecessary delays that take place during the consultation process and there are probably also opportunities for further agreement. If these can be addressed in some way, this offers potential opportunities to both reduce the time that consultation takes and the risks associated with disagreements. Under existing statutory regimes, it appears that there is very little that can be done to attempt to address these issues. That is, there is no mechanism, short of some form of court or regulatory application, to have these issues addressed while the consultation and review process is taking place.

Unfortunately, unlike the issue of who to consult with, it does not seem practical to establish some form of formal determination process for issues that arise during the course of the consultation process. The duty to consult is ongoing and, accordingly, seeking ongoing formal resolution of these issues would likely simply give rise to continuous determinations of where the parties are in carrying out their respective roles and an equally ongoing series of legal challenges. However, it appears that there could be some potential for reducing the delays and disputes that take place during consultation by providing for some form of mediation process as part of the consultation and review process. Providing a party with access to mediation after reasonable efforts have been made to address issues within the consultation process could help resolve some of these issues. It could also encourage the parties to make further attempts to address their issues prior to these being referred to mediation. While this would undoubtedly be a major change to the status quo, it may be worth exploring, given the magnitude and extent of the ongoing issues that can arise during the course of a consultation process. It also benefits from being consistent with one of the objectives of consultation, that is, to encourage discussion between the parties in contrast to litigation.

If the ability to seek the assistance of a mediator has the potential to be of some assistance, what could be done to put this in place? In the absence of a formal requirement, mediation is the subject of agreement. That is, while mediation could be suggested by one of the parties, there is nothing that would compel the other party or parties to participate unless there was a formal requirement to do so. This suggests that some step would have to be taken to establish a formal mediation process that could be called on when appropriate. Ultimately, this may be worth the effort, if even initially only on a trial basis. While mediation does involve some risk, expense, and effort of its own, there is the potential for positive outcomes that could not be achieved between the parties alone, and the parties would always be free to continue to agree to disagree.

\section{Stakeholders, Policy, ANd Politics}

This leaves stakeholders, policy, and politics. What are some of the steps that could be taken to reduce the delays and potential risks associated with these issues? Once again, it seems appropriate to discuss these issues together, given the overlap between them and that steps taken to address one issue may have consequences for another.

The primary issues with stakeholder involvement in energy project review processes appear to be the ones that have already been identified in the discussion of Bill C-38. That is, there is a need to conduct review processes in a way that allows stakeholder involvement. 
However, in some cases, whether legitimate or not, this involvement has the potential to simply overwhelm the process. How can this issue be addressed without creating new risks to the project being reviewed? Some of the policy and political issues simply reflect the flip side of this. Where should the debate on certain policy issues take place and how can this be addressed without giving rise to unnecessary risks? What steps can be taken to avoid the risks of assigning statutory responsibilities to entities who, almost by definition, can be expected to be engaged in political commentary and debate during the course of a statutory review? A final issue that is discussed is stakeholder actions that take place outside of the hearing process.

What can be done in anticipation of potentially thousands of people who want to participate in a review process? While this could be a result of hearing-stacking, it could also simply reflect that there are a large number of people who wish to provide their views, whether positive, negative, or mixed, in the review process. Unfortunately, this has the potential to take significant amounts of time and will inevitably introduce risks of one form or another. On the other hand, prescriptive methods for addressing this issue, at least in the form of those proposed in CEAA 2012, appear to raise risks of their own, along with not necessarily shortening the timing of the process - the primary issue that gave rise to the concerns with this issue in the first place.

Ignoring for the moment the question of stakeholders who might have full procedural rights to participate in any process, it appears that some reasonable solution could be put in place that would allow large numbers of other stakeholders who want to participate to do so, while not fully burdening the review process with the time that this would take to happen. For example, some energy-related statutes have the ability to appoint inquiry officers to undertake certain tasks as part of a broader proceeding. ${ }^{176}$ In statutes where this is already provided for, these officers could be asked to hear or read the majority of the participants' submissions and then summarize and report on these views. In other situations, mechanisms like this could be placed in statutes. While this is clearly a second-best solution, it still appears to satisfy the majority of the objectives associated with this form of stakeholder participation and seems to be a reasonable balance of the various interests affected by this participation. Whether provided for under existing statutes or not, to reduce the legal risks with such a process, it would appear to be preferable to make it clear that this is a procedure that can be resorted to in respect of the review process in question, that this is a procedural issue that does not give rise to legal rights, and that any decision resorting to such a mechanism is unappealable. Alternatively, or in addition, in today's world, there should be other ways of capturing, collating, and sharing this data that does not burden the process in the same way as having a long list of participants make presentations in a linear fashion in a traditional manner.

A more difficult issue is resolving who actually gets to participate in the formal stage of these processes. It appears that any mechanism that leaves this issue up to any questions of interpretation raises significant risks of a subsequent appeal and re-opening of the process. Therefore, given that it does not seem practical to address this risk by allowing everyone to 
participate in a formal hearing, the alternative seems to be to statutorily define who is allowed to participate in formal hearing processes, but to do so in a way that leaves little, if any, opportunity for contrary interpretations (for example, persons whose legal or beneficial rights will be affected by the project). While this might exclude some people from participating as individuals who otherwise would have the right to do so at common law or under some broader definition of an interested party, these individuals would still have other opportunities to participate in other aspects of the review process on their own and potentially even in the formal part of the process as part of a group that does have the formal right to participate. Under a model like this, the process would probably also have to anticipate full participation by some public interest groups to allow a full canvassing of issues.

A step of this nature would likely be the subject of court challenges. However, if the provision were expressed with enough certainty, along with the objectives of the overall scheme, it appears that the interpretation of these provisions could be settled by the courts or through subsequent amendments in reasonably short fashion.

Moving from simply addressing the number of participants in a process to addressing potential issues with the subject of their participation, it appears that the types of steps that have been taken in Bill C-38 in an attempt to more clearly define what issues are intended to be the subject of a given review process are a reasonable first step in addressing this issue. That is, ignoring any discussion over where the federal government appears to be trying to draw the line regarding the scope of federal assessments, it appears to be a good idea to attempt to more clearly define what is in scope and what is out of scope in any given statutory review process, and any individual review. While this is unlikely to resolve the differences that exist between participants at a policy level, or all of the risks associated with this issue, it should at least provide some further certainty and reduce the risks and delay associated with submissions that clearly go beyond the matters in issue. While some review processes appear to cope with this issue better than others, it would likely be beneficial to consider whether further steps could be taken from this perspective under other statutory regimes and individual reviews.

This, of course, begs the question of what happens to the discussion of the issues that are out of scope or otherwise beyond the jurisdiction or role of a particular entity in a review process. While it may seem that this should not be a particular concern once there is a better articulation of what is within scope, from a practical perspective it is not as if these opinions will simply go away because they are found to be not within scope, and it is these debates that often represent the greatest risks to a project - and to the governments in place at the time of these discussions. Accordingly, it may be worthwhile considering what can be done about this.

One answer is to simply allow this debate to take place in cyberspace and other mediums, as much of it now does. However, this appears to have led to more than one unsatisfactory outcome in the past. Accordingly, another potential alternative is for the government in question to actually provide a forum where information and views on these broader policy questions can be exchanged. While it is not expected that this would be a panacea, one of the reasons that the broader policy discussions seem to unfold in the way that they do is because 
participants feel that they have not had an opportunity to provide input on a particular policy and that that policy is effectively dictating the outcome of the review process in question, or that information is not available on when a particular policy decision was made and on what basis. Providing an opportunity to provide input and views on these issues (outside of a review process) may mitigate some of the negative effects of a completely unstructured debate on these topics. Further, from a purely legal standpoint, providing an alternative forum could also provide further evidence to a judge of the relevant government's intent from a scoping perspective and help support that decision.

The third topic is the risks that are created when statutory duties are performed by politicians. This risk appears to be the starkest under CEAA 2012, given the steps that have been taken to more clearly define the roles and responsibilities of various entities under the process and to specifically assign certain responsibilities to the Minister and the GIC. However, it also exists to varying extents in other energy review processes.

Whenever a statutory responsibility is assigned to a minister of the Crown, this increases the risk that the exercise of that responsibility will be more susceptible to challenge as a result of the Minister's various, and potentially competing, roles, including as a member of government. Given this, one alternative is to consider whether the Minister actually needs to fulfil this role or whether there are others who do not have political responsibilities who could do so. Interestingly, many of the statutory duties that are assigned to ministers are, in fact, sub-delegated to other officials. While this likely provides some protection against concerns about a minister's political beliefs influencing his statutory duties, many of these instances of sub-delegation are not apparent to the public. As a result, to avoid unnecessary debates on these topics, it may be an idea to expressly assign these responsibilities to other officials rather than rely on unknown sub-delegations of power.

For powers that remain with a minister or a provincial or federal cabinet, the choice seems to be clear. Either avoid any discussion or comments about a particular energy project, its review process, or other related issues (or risk the potential consequences of this) or, as was the case in Inuit Tapirisat, make it beyond doubt in the statutory assignment of the power in question that when the power is being exercised, it is being exercised as part of the executive powers of the government and is not constrained by either the statute in question or issues of common law.

The last topic that will be addressed under this heading is the role of intervener groups, and sometimes non-interveners, in activities outside of formal project review processes. While, again, this is not directly connected with review processes themselves, this practice almost invariably occurs during major energy project review processes and does have the potential to influence the outcome of these processes. Historically, these activities took place through letters to the editor, call-in talk shows, and the like. Increasingly, project opponents now turn to cyberspace and social media to promote their views. The current state of the art appears to involve activities both inside and outside of the formal review process.

Given that most of us appear to enjoy living in a democratic society, it is difficult to suggest that project opponents should not be allowed to engage in whatever legal activities are available to them to disseminate and promote their views, even if this occurs outside of 
the formal review process. However, at the same time, these activities can have the potential to seriously affect the nature and credibility of the review processes themselves, which in many cases appears to be their goal. Given this, is this still a legitimate activity, particularly when it is being engaged in by stakeholders who are also participating in these very review processes?

As indicated, it is difficult to control free speech outside the hearing process. However, there may be ways of influencing some of what is said in other forums. One ad hoc means of addressing this issue that has achieved some success is using the statements made by hearing participants outside of review processes in cross-examination during the course of the review process, just as statements made by a proponent can potentially be used against them. This can sometimes result in the realization that the person being cross-examined should have been more careful in their statements or those of their colleagues; however, because this opportunity generally does not take place until late in the review process, this does not have any effect on the impact of the previous statements at the time that they were made. As a result, by the time that a proposed project gets to the hearing stage, most of the damage associated with these outside activities will likely have been done.

One potential means of addressing this, although again not a panacea, could be to require those parties who have registered to participate in a project review process to formally file and affirm anything that they distribute outside of the review process in the review process itself. If this is a condition of participating, there is some chance that this could cause statements that are made by these participants outside of the hearing process to be more closely considered. This would not necessarily change the statements that are made by nonparticipants in the hearing process but may offer further opportunities for engaging in the public aspects of these debates.

\section{ConCLUSION}

This article has touched on some of the current concerns associated with major energy project review processes in Canada, including some of the potential impacts of Aboriginal, stakeholder, and political influences on these processes. While many people engaged in the debate about how Bill C-38 proceeded through Parliament, and how it addresses certain issues, the mere fact that this debate occurred at the level that it did underlines the significance of this issue. A review of Bill C-38 suggests that, while it does appear to be directed at a number of the issues that are impacting major energy review processes, some of the means that are proposed to address these may not be as successful in achieving their objectives as presumably hoped for. Many of the issues that Bill C-38 attempts to address also exist in other energy project review processes. There are also other issues, such as Aboriginal ones, that are not currently addressed in any substantive way in these regimes. While a discussion of some of these issues and potential means of addressing them highlights the complexities associated with them, it also appears to suggest that there may be steps that could be taken to reduce some of the delays, costs, and risks that are currently being experienced. It also appears to highlight the potential benefits of engaging in a broader discussion of these issues to attempt to address what can be done to ensure that these review processes take place in an appropriate manner but, at the same time, do not result in unnecessary impacts on the Canadian energy industry or the Canadian economy as a whole. 